\title{
Diagnosis and empirical treatment of fever of unknown origin (FUO) in adult neutropenic patients: guidelines of the Infectious Diseases Working Party (AGIHO) of the German Society of Hematology and Medical Oncology (DGHO)
}

\author{
W. J. Heinz ${ }^{1}$ - D. Buchheidt ${ }^{2}$ - M. Christopeit ${ }^{3} \cdot$ M. von Lilienfeld-Toal ${ }^{4}$ • \\ O. A. Cornely ${ }^{5,6,7,8,9}$ - H. Einsele ${ }^{1}$ - M. Karthaus ${ }^{10,18} \cdot$ H. Link $^{11} \cdot$ R. Mahlberg ${ }^{12}$ • \\ S. Neumann ${ }^{13} \cdot$ H. Ostermann ${ }^{14}$ - O. Penack ${ }^{15}$ - M. Ruhnke ${ }^{16} \cdot$ M. Sandherr ${ }^{17}$. \\ X. Schiel ${ }^{18}$ • J. J. Vehreschild ${ }^{5,6}$ • F. Weissinger ${ }^{19} \cdot$ G. Maschmeyer ${ }^{20}(\mathbb{D}$
}

Received: 3 May 2017 / Accepted: 6 August 2017 /Published online: 30 August 2017

(C) The Author(s) 2017. This article is an open access publication

\begin{abstract}
Fever may be the only clinical symptom at the onset of infection in neutropenic cancer patients undergoing myelosuppressive chemotherapy. A prompt and evidence-based diagnostic and therapeutic approach is mandatory. A systematic search of current literature was conducted, including only full papers and excluding allogeneic hematopoietic stem cell transplant recipients. Recommendations for diagnosis and
\end{abstract}

Electronic supplementary material The online version of this article (doi:10.1007/s00277-017-3098-3) contains supplementary material, which is available to authorized users.

G. Maschmeyer

gmaschmeyer@klinikumevb.de

1 Department of Internal Medicine II, University of Würzburg Medical Center, Würzburg, Germany

2 Department of Internal Medicine-Hematology and Oncology, Mannheim University Hospital, Mannheim, Germany

3 Department of Stem Cell Transplantation, University Hospital UKE, Hamburg, Germany

4 Department of Hematology and Oncology, University Hospital of Jena, Jena, Germany

5 Department I for Internal Medicine, University Hospital of Cologne, Cologne, Germany

6 German Centre for Infection Research, partner site Bonn-Cologne, Cologne, Germany

7 Clinical Trials Centre Cologne, ZKS Köln, Cölogne, Germany

8 Center for Integrated Oncology CIO Köln-Bonn, Cologne, Germany

9 Cologne Excellence Cluster on Cellular Stress Responses in Aging-Associated Diseases (CECAD), Medical Faculty, University of Cologne, Cologne, Germany

therapy were developed by an expert panel and approved after plenary discussion by the AGIHO. Randomized clinical trials were mainly available for therapeutic decisions, and new diagnostic procedures have been introduced into clinical practice in the past decade. Stratification into a high-risk versus low-risk patient population is recommended. In high-risk patients, initial empirical antimicrobial therapy should be active Neuperlach and Klinikum Harlaching, München, Germany

11 Hematology and Medical Oncology Private Practice, Kaiserslautern, Germany

12 Klinikum Mutterhaus der Borromäerinnen, Trier, Germany

13 Medical Oncology, AMO MVZ, Wolfsburg, Germany

14 Department of Hematology and Oncology, University of Munich, Munich, Germany

15 Internal Medicine, Hematology, Oncology and Tumor Immunology, University Hospital Charité, Campus Virchow Klinikum, Berlin, Germany

16 Department of Hematology and Oncology, Paracelsus-Klinik, Osnabrück, Germany

17 Hematology and Oncology Practice, Weilheim, Germany

18 Department of Hematology, Oncology and Palliative Care, Klinikum Harlaching, Munich, Germany

19 Department of Internal Medicine, Hematology, Oncology and Palliative Care, Evangelisches Klinikum Bethel, Bielefeld, Germany

20 Department of Hematology, Oncology and Palliative Care, Klinikum Ernst von Bergmann, Potsdam, Germany 
against pathogens most commonly involved in microbiologically documented and most threatening infections, including Pseudomonas aeruginosa, but excluding coagulase-negative staphylococci. In patients whose expected duration of neutropenia is more than 7 days and who do not respond to first-line antibacterial treatment, specifically in the absence of moldactive antifungal prophylaxis, further therapy should be directed also against fungi, in particular Aspergillus species. With regard to antimicrobial stewardship, treatment duration after defervescence in persistently neutropenic patients must be critically reconsidered and the choice of anti-infective agents adjusted to local epidemiology. This guideline updates recommendations for diagnosis and empirical therapy of fever of unknown origin in adult neutropenic cancer patients in light of the challenges of antimicrobial stewardship.

Keywords Neutropenia $\cdot$ Fever $\cdot$ Empirical therapy ·

Antibacterial $\cdot$ Antifungal $\cdot$ Infection

\section{Introduction}

Neutropenic cancer patients have a high risk of infectious complications, depending on the extent and duration of neutropenia, as well as on additional cellular and/or humoral immunosuppression and disruption of skin and mucosal barriers. Duration and nadir of neutropenia are correlated with the incidence of fever and infections [1], which not only cause significant morbidity and mortality [2] but may also compromise further chemotherapy. At onset of fever of unknown origin (FUO) in neutropenic patients, prompt and effective evidence-based intervention is required.

In the past decade, an increasing rate of resistance among bacterial pathogens to widely used antibacterial agents, particularly beta-lactams and fluoroquinolones, has been noted. At the same time, only a small number of newer antimicrobial agents have become available, e.g., tigecycline, linezolid, moxifloxacin, cefozopran, telavancin, oritavancin, ceftazidime-avibactam, ceftolozan-tazobactam, or micafungin; however, data on their empirical use in neutropenic patients are limited or not existent. Efficacy and safety of anti-infective strategies have to be reassessed in this context. Newly introduced diagnostic tests and data on the usefulness of biomarkers for therapeutic decisions are to be critically reconsidered.

This guideline, an update of a version from 2003 [3], focuses on risk-adapted diagnostic procedures and empirical antimicrobial treatment in neutropenic cancer patients with FUO according to their likelihood of a complicated course of infection.

Separate AGIHO guidelines for hematological and oncological patients have been published on sepsis [4], primary prophylaxis of bacterial [5] and fungal infections [6], prevention of infections after allogeneic hematopoietic stem cell transplantation (HSCT) [7], diagnosis and treatment of invasive fungal infections [8,9], management of pulmonary infiltrates [10], abdominal complications [11], venous catheter related infections [12], central nervous system infections [13], infections after autologous HSCT [14], and community respiratory viral infections [15].

\section{Guideline development, grading of recommendations, and definitions}

A group of hematologists, oncologists, and infectious disease specialists was built within the AGIHO, which after thorough literature search (including only full publications but excluding allogeneic HSCT), created a set of core slides with statements and recommendations, discussed in face-to-face meetings, telephone conferences, and by electronic correspondence. The final version was approved in an AGIHO plenary meeting on 10 February 2017. This manuscript was reviewed by all co-authors. A detailed methodological report is provided in the Electronic supplementary material.

Consistent with recently updated AGIHO guidelines, the grading system currently used by the European Society for Clinical Microbiology and Infectious Diseases [16] (Table 1) was adapted.

\section{Definitions}

Neutropenia There is no defined cut-off value for the neutrophil count clearly separating patients with or without increased risk of infections and mortality. In line with most recommendations and risk stratifications in clinical trials, a neutrophil count (segments and bands) $<500 / \mu l$ or $<1000 /$ $\mu l$ with a predicted decline to $<500 / \mu l$ within the next 2 days defines neutropenia.

Fever Different definitions of fever in neutropenia have been used in guidelines and clinical trials, and several methods and sites to determine the body temperature are available. In general, either a temperature measured orally of $\geq 38.3^{\circ} \mathrm{C}$ once or $\geq 38.0^{\circ} \mathrm{C}$ lasting for at least $1 \mathrm{~h}$ or being measured twice within $12 \mathrm{~h}$ or a method shown to be equivalent to these results may be used to define fever. In the absence of a definite noninfectious cause, such as a febrile reaction to cytokines, cytotoxic drugs (e.g., cytarabine or bleomycin), or a transfusion of blood products, this clinical symptom has to be regarded as a sign of an infectious complication. It should be kept in mind that fever may be obscured by antipyretic drugs used for analgesia or cancer treatment, such as prednisone, non-steroidal anti-inflammatory agents, or metamizole (dipyrone). 
Table 1 Grading system used in the present guideline (adapted from [16])

$\begin{array}{ll}\text { Strength of recommendation } & \text { AGIHO } \\ \text { Grade A } & \text { Strongly supports a recommendation for use } \\ \text { Grade B } & \text { Moderately supports a recommendation for use } \\ \text { Grade C } & \text { Marginally supports a recommendation for use } \\ \text { Grade D } & \text { Supports a recommendation against use } \\ \text { Quality of evidence } & \\ \text { Level I } & \begin{array}{l}\text { Evidence from at least } 1 \text { properly designed randomized, controlled trial } \\ \text { Level II }\end{array} \\ & \begin{array}{l}\text { Evidence from at least } 1 \text { well-designed clinical trial, without randomization; from cohort or case-controlled } \\ \text { analytic studies (preferably from } \geq 1 \text { center); from multiple time series; or from dramatic results of uncon- } \\ \text { trolled experiences } \\ \text { Evidence from opinions of respected authorities, based on clinical experience, descriptive case studies, or reports } \\ \text { of expert committees }\end{array}\end{array}$

${ }^{\text {a }}$ Added index: meta-analysis or systematic review of randomized controlled trials $(r)$; transferred evidence, that is, results from different patient cohorts or similar immune-status situation $(t)$; comparator group is a historical control $(h)$, and uncontrolled trial $(u)$

\section{Risk stratification}

While it is widely accepted that the incidence of infections in cancer patients is directly related to nadir and duration of neutropenia [1], it is difficult to exactly predict this in an individual patient [17]. Clinical trials on treatment of fever and infections in patients with short periods of neutropenia, e.g., below 5 or 7 days, are limited, and some patients with neutropenia lasting for more than 5 days have also been enrolled in studies including oral therapy and outpatient care [18, 19]. As a result of a literature review, we have agreed upon stratification into two risk groups, i.e.,

Standard risk: expected duration of neutropenia of up to 7 days and

High risk: expected duration of neutropenia of at least 8 days.

Table 2 MASCC score to identify standard-risk patients with respect to a complicated course of a febrile episode [17]

\begin{tabular}{ll}
\hline Characteristic & Weight \\
\hline Burden of febrile neutropenia with no or mild symptoms ${ }^{\mathrm{a}}$ & 5 \\
No hypotension (systolic blood pressure $>90 \mathrm{mmHg}$ ) & 5 \\
No chronic obstructive pulmonary disease & 4 \\
$\begin{array}{l}\text { Solid tumor or hematologic malignancy with no previous fungal } \\
\quad \text { infection }\end{array}$ & 4 \\
No dehydration requiring parenteral fluids & 3 \\
Burden of febrile neutropenia with moderate symptoms & 3 \\
Outpatient status & 3 \\
Age $<60$ years & 2
\end{tabular}

A score of $\geq 21$ identifies a standard-risk patient

a Points attributed to the variable "burden of febrile neutropenia" are not cumulative and the maximum theoretical score is therefore 26
However, while all patients with neutropenia lasting eight or more days are regarded as high-risk patients with respect to a complicated course of a febrile episode, those assigned to the standard-risk group may exhibit individual characteristics justifying their allocation to the high-risk population as well. These individual factors can be identified by the use of the Multinational Association of Supportive Care in Cancer (MASCC) criteria [17], which have been repeatedly validated [19-21] and are shown in Table 2.

Standard-risk patients with a MASCC score of $\geq 21$ constitute a group of patients with a high likelihood of a noncomplicated clinical course of infection. Provided they meet all individual criteria listed in Table 3, primary outpatient management of neutropenic fever is possible (BIIr).

\section{Epidemiology}

\section{Most common pathogens identified in febrile neutropenic patients with microbiologically documented infections}

At onset of fever, antibiotic therapy needs to be started immediately, and because of the time needed for microbiological tests, it will have to be empirical in the beginning in patients who also do not show a suspected clinical focus of infection. In about half of patients with febrile neutropenia, the antibiotic therapy will remain empirical, since no relevant pathogen or focus of infection can be identified during the following days [19, 22]. The grounds for selection of empirical antimicrobial agents are (a) reported results of prospective, randomized clinical studies and (b) microorganisms identified in patients with microbiologically documented infections by analogy. Here, Staphylococcus aureus, Streptococcus spp., enterococci, coagulase-negative staphylococci, gram-negative enterobacteria, and Pseudomonas aeruginosa are the most frequent and relevant 
Table 3 Individual criteria to be fulfilled by patients to be treated primarily on an outpatient basis

$\begin{array}{ll}\text { General } & \text { No signs of } \mathrm{CNS}^{\mathrm{a}} \text { infection, severe pneumonia, or venous catheter infection } \\ & \text { No signs of sepsis or shock } \\ & \text { None of the following: associated organ failure, pronounced abdominal pain ( } \pm \text { diarrhea), dehydration, recurrent vomiting, } \\ & \text { intravenous supportive therapy, necessity of permanent or close monitoring (e.g., metabolic decompensation, hypercalcemia) } \\ & \text { No new ECG abnormalities requiring treatment } \\ & \text { No new severe organ impairment } \\ \text { Oral antibiotics } & \text { No fluoroquinolone prophylaxis or therapy within the last } 7 \text { days } \\ & \text { Oral medication feasible } \\ & \text { Good compliance with oral medication expected } \\ \text { Outpatient } & \text { Medical care ensured (different options) } \\ \text { management } & \text { Patient does not live alone; patient/helpers have a telephone; patient can reach clinic skilled at treatment of neutropenic patients } \\ & \text { within } 1 \mathrm{~h}\end{array}$

${ }^{\mathrm{a}} \mathrm{CNS}$, central nervous system

pathogens [23, 24]. While numerically, coagulase-negative staphylococci are the most frequent microbial isolates in many institutions, a single blood culture positive for those commensal skin pathogens, in lack of a corresponding clinical focus of infection, should be considered contamination [25]. The same is true for other potential contaminants like Corynebacterium, Bacillus cereus, Propionibacterium, or Micrococcus spp. Among fungal pathogens, Candida spp. and Aspergillus spp. are predominant, the latter typically being associated with a prolonged duration of neutropenia in high-risk patients [26].

\section{Local epidemiology and impact of oral fluoroquinolone prophylaxis}

A recent history of antibiotic prophylaxis or therapy increases the risk of infections due to bacterial pathogens resistant to the antibiotic used [27-29]. After ciprofloxacin prophylaxis, a relative predominance of infections caused by gram-positive cocci compared with gram-negative bacteria has been observed [30]. Quinolones have been reported as being associated with an increased rate of colonization by vancomycinresistant enterococci (VRE) [31, 32] or methicillin-resistant S. aureus (MRSA) [33] and with a higher prevalence of multidrug resistance among enterobacteria via extended-spectrum beta-lactamases (ESBL) [34, 35]. Colonization by ESBL, VRE, or MRSA has been associated with an increased rate of bacteremia with these pathogens [32, 36-38]. As a consequence, the use of quinolones for interventional treatment in febrile neutropenic patients should be limited to microbiologically documented infections caused by in vitro susceptible microorganisms [39].

The local epidemiology must be taken into account for the appropriate choice of empirical antimicrobial therapy. Microbiological findings from patients treated in a defined hematology-oncology institution should be discussed on a regular basis, i.e., at least once a year, with infection-control and antimicrobial stewardship experts (BIII). Baseline screening of newly or re-admitted patients for multidrug-resistant pathogens, i.e., MRSA (BIII), VRE (BIII), and ESBL (BIIt), should be considered.

\section{Diagnosis}

\section{Baseline diagnostic procedures before immunosuppressive therapy}

Before starting myelosuppressive therapy, patients must be thoroughly explored for relevant previous or prevalent infections, which may become relevant during treatment-induced neutropenia (AIII). Clinical examination should be performed with special attention paid to skin, mucosa, puncture, and vascular catheter exit sites, paranasal sinuses, lungs, and the perianal region (AIII). In patients with a self-reported penicillin allergy, skin testing is recommended (BIIt), as a negative result (which is to be expected in the vast majority of cases) helps to avoid unnecessary first-line use of carbapenems, aztreonam, or vancomycin [40-42].

Baseline laboratory tests include a blood count, liver enzymes (ASAT/SGPT, ALAT/SGOT, gGT), total bilirubin, alkaline phosphatase, LDH, creatinine, blood urea nitrogen, coagulation tests (INR, aPTT), C-reactive protein, and urinalysis (BIII). Except for urinalysis, it is recommended to repeat these tests regularly, e.g., twice a week, during long-lasting neutropenia (BIII). Procalcitonin or cytokine levels (such as interleukin6) are not recommended for routine baseline diagnostics (DIII).

If neither computed nor magnetic resonance tomography of chest and abdomen have been performed for staging of the underlying disease, chest radiographs (two views) and abdominal ultrasound may be considered a baseline examination before first chemotherapy to check for pre-existing abnormalities and facilitating comparison with subsequent studies (CIII). Particularly in high-risk patients, a thoracic CT scan prior to 
chemotherapy appears desirable for documentation of baseline status. However, in the absence of prospective studies, no recommendation can be made. In patients with a history of an invasive infection, appropriate imaging is recommended even in the absence of clinical symptoms of recurrence (BIII).

\section{Screening of asymptomatic neutropenic patients for invasive fungal infections}

For high-risk patients with an expected duration of profound neutropenia $>7$ days, serial (at least twice weekly) monitoring for Aspergillus galactomannan in serum has been recommended $[43,44]$. Monitoring patients with 1,3-beta-D-glucan in blood samples $[45,46]$ is being discussed as an alternative but rarely used due to higher costs. A sensitive, validated Aspergillus PCR may also be helpful (CIII) for screening of blood samples in specific high-risk populations [47]. However, the sensitivity of these tests is strongly reduced in patients given systemic moldactive antifungals [48, 49], and false-positive results may be caused by beta-lactam antibiotics, parenteral nutrition, severe intestinal mucositis, or transfusion of blood products. Therefore, screening of afebrile and asymptomatic patients should be restricted to those not receiving systemic mold-active prophylaxis (BIIu). These non-culture-based procedures do not replace clinical, imaging, endoscopic, or other microbiological diagnostics (BIII). Details on early diagnosis of fungal infections are discussed in a separate guideline [8].

\section{Diagnostic procedures at onset of fever in neutropenia}

Diagnostic measures at first fever in neutropenic patients aim at

(a) Ruling out non-infectious causes of fever

(b) Identifying a clinical focus and/or causative pathogens, and

(c) Assessing the severity of inflammatory response in order to early identify patients in need for intensive care
They must not delay the start of appropriate antibiotic therapy (AIIt) [50-53]. In a clinically unstable patient, eventually presenting in the emergency room, prompt start of antimicrobial therapy is required (AI) and immediate referral to an intensive care unit must be considered [8].

Thorough clinical examination must be updated (AIII) and repeated at least daily as long as a hospitalized patient is febrile (AIII). It may reveal a presumable focus of infection and enable a pre-emptive antimicrobial treatment targeting typically involved pathogens rather than purely empirical treatment (Table 4).

A minimum of two separate pairs of blood cultures must be taken prior to initiation of antibiotic therapy (AIII). There is no need to wait between sampling of cultures; separate sets can be achieved by venipuncture of both arms. If the patient has an indwelling central venous catheter (CVC), one pair should be drawn from a peripheral vein and at least one from the CVC. The diagnostic yield of this approach can be increased by taking a blood sample from each lumen of a CVC and by taking three pairs of blood cultures (60 ml blood) (BIIt) [54-56]. A "differential time to positivity" of $\geq 2 \mathrm{~h}$ between CVC and peripheral blood cultures may indicate a CVC-related infection [57, 58] and give reason for pre-emptive treatment described in a separate guideline [59] (BIlu). Multiplex PCR-based methods do not replace the standard microbiology (CIIu) [60-64] but may improve turnaround time, sensitivity, and specificity of pathogen detection [59]. A reduction in morbidity or mortality in febrile neutropenic patients through the use of PCR-based methods supplementing blood cultures has not yet been shown.

In addition to repeat baseline laboratory tests described above, determination of lactate, blood gas analysis, and coagulation tests, in order to early identify severe sepsis, should be considered (BIII). Biomarkers such as procalcitonin or interleukin- 6 are widely used for assessing the severity of inflammation, but data on their prognostic or predictive value in adult patients with febrile neutropenia are conflicting [65-70]. In high-risk patients who did receive systemic mold-active antifungal prophylaxis and were not screened for Aspergillus galactomannan, beta-D-glucan, or fungal

Table 4 Pathogens typically involved in clinically documented infections

\begin{tabular}{ll}
\hline Clinical signs and symptoms & Frequently involved pathogens \\
\hline Erythema and/or pain at venous access & Coagulase-negative staphylococci \\
Mucosal ulcers & Alpha-hemolytic streptococci, Candida spp. \\
Single point-like skin lesions & Gram-positive cocci, Candida spp. \\
Necrotizing skin lesions & Pseudomonas aeruginosa, filamentous fungi \\
Diarrhea, meteorism & Clostridium difficile \\
Enterocolitis, perianal lesions & Polymicrobial (incl. anaerobes) \\
Lung infiltrates \pm sinusitis & Filamentous fungi, Pneumocystis jirovecii \\
Retinal infiltrates & Candidemia \\
\hline
\end{tabular}


PCR, such a test (preferably galactomannan) should be ordered at this time to enable early detection of a breakthrough invasive fungal disease (BIII).

At onset of fever, a CT scan of the lungs is recommended in the case of respiratory tract symptoms (BIII). Conventional chest radiographs are discouraged (DIIt), as they show abnormalities in less than $2 \%$ of febrile neutropenic patients who have no clinical signs of lower respiratory tract infection [71-73]. Nasal congestion or signs and symptoms of sinusitis should give reason for a CT scan of paranasal sinuses (BIII) [74]. First data on PET-CT indicate a potential use for early identification of the source of fever/infection, particularly abdominal foci [75-78]. Despite these positive reports, an explicit recommendation for its routine use cannot be given due to the lack of systematic studies.

Gastrointestinal complaints or laboratory abnormalities should prompt abdominal ultrasonography (BIIu). An abdominal CT scan is an alternative if neutropenic enterocolitis is suspected (BIIu) [11, 79, 80].

\section{Antimicrobial therapy}

The following recommendations are based on evidence from controlled studies and clinical experience. The status of approval by regulatory agencies and reimbursement policies have not been taken into account.

A clinical treatment algorithm for high-risk patients is depicted in Fig. 1.

\section{Antibacterial agents for empirical first-line therapy}

In high-risk patients, the spectrum of first-line antibacterial agents should include gram-negative enterobacteria, $P$. aeruginosa, $S$. aureus, and streptococci (AI), while local epidemiology must be taken into account. Treatment must be started within $2 \mathrm{~h}$ after onset of fever, without awaiting the results of microbiology (AIIt) [50-53]. If oral fluoroquinolone prophylaxis has been given, it should be discontinued at the start of interventional antimicrobial therapy (AIII). Emergency treatment algorithms for this clinical situation as well as supervision or audits have been shown to improve timely and adequate therapy [81]. Piperacillin/tazobactam, imipenem, meropenem, cefepime, ${ }^{1}$ and ceftazidime are suitable for first-line empirical antibacterial monotherapy in severely neutropenic high-risk patients with FUO (AI). Most patients with a history of penicillin allergy will tolerate imipenem, meropenem, or an antipseudomonal cephalosporin. For the small cohort of patients with severe immediate-type

\footnotetext{
${ }^{1}$ A first meta-analysis of cefepime in this setting had indicated an excess mortality compared with other antibiotics [82]; however, after data reevaluation by the US-FDA, this was not confirmed and approval was not changed $[83,84]$.
}

hypersensitivity reaction, aztreonam [85] may be used as aless well-studied - alternative (CIIu). In this setting, the addition of a vancomycin or teicoplanin to aztreonam may be considered due to the lack of activity of aztreonam against gram-positive bacteria (CIII) [86].For newer broad-spectrum antibacterial agents, such as ertapenem [87], which has insufficient activity against Pseudomonas spp., doripenem [88], ceftazidimeavibactam [89], ceftolozane-tazobactam [64, 90], or cefozopran [91], there is very limited data on their safety and efficacy for empirical treatment in adult febrile neutropenic cancer patients available so far. Tigecycline in combination with an antipseudomonal beta-lactam has shown benefit in terms of a lesser need for treatment modification in institutions with excess rates of multidrug-resistant pathogens [92] and for 2nd- or 3rd-line treatments [93].

\section{Antibacterial combination therapy}

In high-risk patients, there is no evidence for superior efficacy of a combination of antibacterial agents compared with monotherapy (AIIr) [94]. Combining antibacterial agents in this indication has also not been shown to prevent the development of resistance [95]. A combination might be useful in institutions with a high prevalence of multidrug-resistant bacteria (AIIr) [92]. An antipseudomonal beta-lactam should always be included, with an aminoglycoside or a fluoroquinolone such as levofloxacin and ciprofloxacin as the combination partner (AIIt). For standard-risk patients without critically impaired renal function, the combination of an aminoglycoside with a third- or fourthgeneration cephalosporin can be considered (AI) [96-98]. When aminoglycoside antibiotics are given, therapeutic drug monitoring is mandatory (AIIu) and once-daily dosing is appropriate (AIIr) [99].

A combination therapy including vancomycin or teicoplanin (DIIr) or linezolid (DIII) is generally discouraged for empirical first-line therapy [100] but might be considered in the case of (CIII) severe mucositis, skin or soft tissue infection, foreign body infection, or documented colonization of a patient with MRSA. The use of vancomycin is associated with an increased risk of nephrotoxicity, which should be diminished by therapeutic drug monitoring (BIIt). Although a higher rate of VRE infections has been found in VRE-colonized patients [31, 32, 101], the addition of linezolid to empirical first-line treatment has not shown a significant benefit [102]. Beyond this, the risk of thrombocytopenia as one of the major potential side effects of linezolid has to be considered.

\section{Empirical first-line antibacterial therapy in standard-risk patients with FUO}

The recommendations in this paragraph affect patients with an expected duration of neutropenia $\leq 7$ days who typically are not receiving systemic fluoroquinolone prophylaxis. 


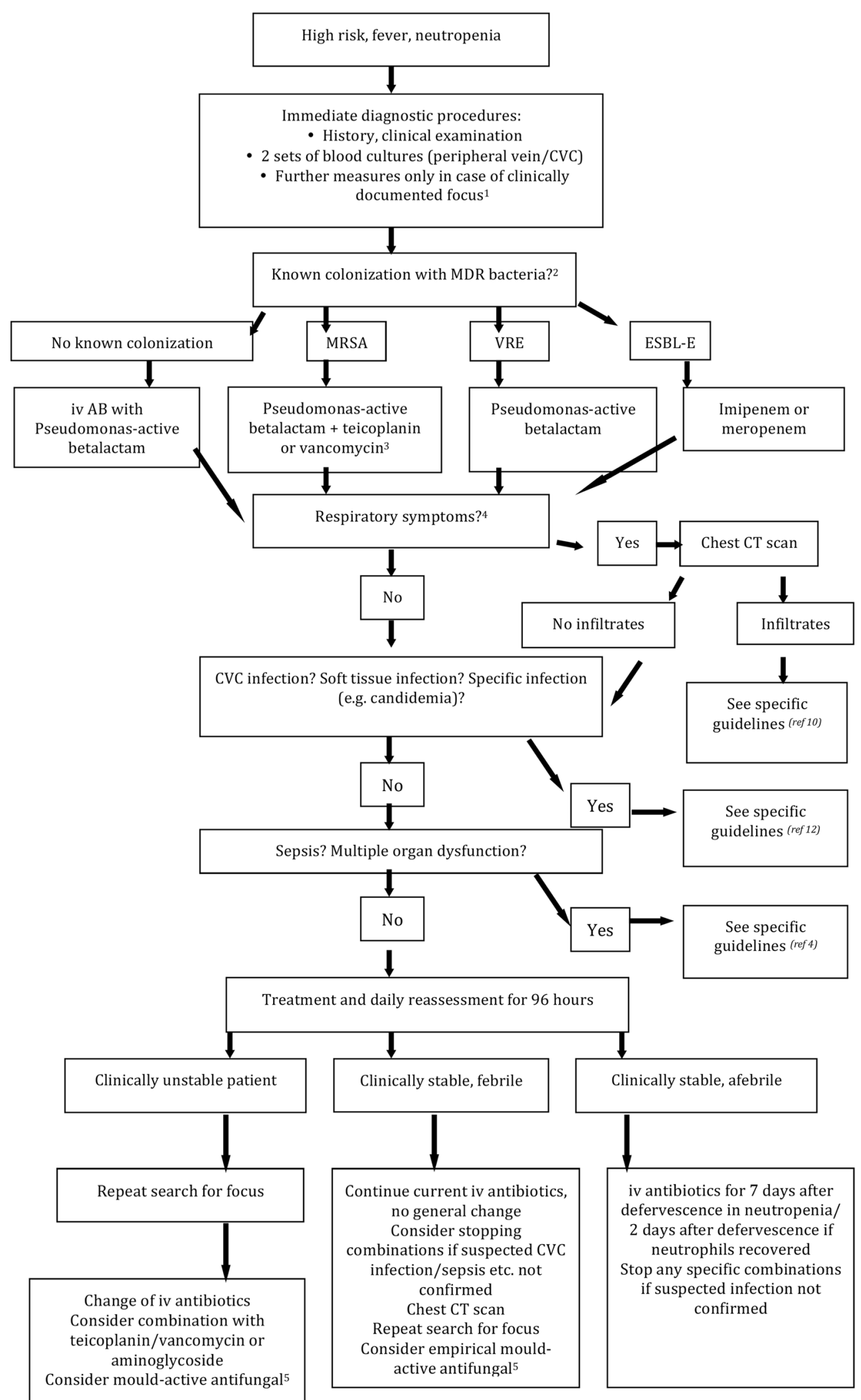

Fig. 1 Treatment algorithm for febrile neutropenic high-risk patients: 1, e.g., urine cultures, CT of sinuses, echocardiography, and viral PCR; 2 , in the case of carbapenem-resistant MDR bacteria individual choice according to in vitro susceptibility; 3 , monitor blood levels; 4 , e.g., tachypnea, dyspnea, cough, and pleuritic symptoms; 5 , strong recommendation for patients with high-risk neutropenia without mold-active prophylaxis. $C V C$ central venous catheter, $M D R$ multidrug resistant, $C T$ computed tomography scan, $i v$ intravenous, $A B$ antibiotics, MRSA methicillin-resistant Staphylococcus aureus, $E S B L-E$ extended spectrum beta-lactamase-producing enterobacteria, $V R E$ vancomycin-resistant enterococci, $P C R$ polymerase chain reaction 
For patients with $\leq 7$ days of neutropenia and no high-risk criteria identified by the MASCC score (Table 2) and without practical obstacles to outpatient management (Table 3), oral and outpatient therapy is recommended (AI) [103]. Hospitalization and in-patient start of antibacterial therapy, with a change to an outpatient treatment after defervescence or stabilization within the first 2 days, is an alternative approach validated in clinical studies (AI) [18, 19, 104].

Safety and feasibility of oral outpatient therapy for standardrisk patients identified by the MASCC score has recently been confirmed in a randomized prospective multicenter study, with less than $10 \%$ complications in the total study population and only $5 \%$ of patients requiring readmission under moxifloxacin monotherapy compared with a twice-daily combination of amoxicillin/clavulanate and ciprofloxacin [19]. For oral antibiotic therapy in standard-risk patients, a combination of amoxicillin/ clavulanate with ciprofloxacin or monotherapy with moxifloxacin appears feasible (AI). Moxifloxacin is not active against $P$. aeruginosa $[105,106]$. In the case of confirmed penicillin allergy, amoxicillin/clavulanate may be replaced by clindamycin [107] or cefuroxime axetil (BIIu) [108]. Primary intravenous therapy for patients of the standard-risk group may consist either of a monotherapy with ceftazidime, cefepime, or piperacillin/tazobactam, or, in the case of an increased rate of multiresistant gram-negative bacteria, of a combination of a third- or fourth-generation cephalosporin with an aminoglycoside $(\mathrm{AI})$.

\section{Monitoring of inflammatory laboratory parameters during first-line empirical antibacterial therapy}

Increasing CRP on day 5, compared with day 1, might indicate an unfavorable course of the episode [109]. Elevated procalcitonin may point at severe infection or sepsis in high-risk patients [65, 110-112]. Also, monitoring of procalcitonin on day 2 after onset of fever may help to detect a minority of patients with potentially severe infections, and in the case of persistent fever, it may contribute to early diagnosis of invasive mycoses [113]. Rising interleukin-6 typically indicates an unresolved infection/inflammation, while low levels have a high negative predictive value making severe septic infection unlikely [65-67, 114-117]. None of these parameters should be used alone for clinical decisionmaking (BIII).

\section{Re-evaluation of patients after $\geq 96 \mathrm{~h}$ of first-line empirical antibacterial therapy}

After $\geq 96 \mathrm{~h}$ of persistent or recurrent fever despite adequate therapy, a multislice pulmonary CT scan (AIIu) [10, 118, 119] should be performed (preferably within $24 \mathrm{~h}$ after indication), independent of respiratory symptoms (AIIu). Other imaging procedures are indicated according to clinical signs or symptoms of a localized infection (BIIu). A thorough physical examination must be reiterated, with inspection of the oropharynx, skin lesions with particular attention to venous access and puncture sites and the perianal region, as well as painfulness of paranasal sinuses or other signs of upper airway infection (Table 4). Blood cultures from peripheral vein and indwelling central venous catheters should be repeated, while other microbiological cultures are only useful if clinical signs or symptoms indicate a possible site of infection (BIIu).

\section{Modifying antibiotic treatment in non-responders}

If diagnostic procedures reveal a clinically documented infection or if a causative pathogen has been isolated, the empirical antibacterial approach should be changed to targeted or preemptive therapy (AIIt). Pre-emptive antimicrobial treatment is chosen according to the spectrum of microorganisms typically involved in the respective clinically documented infection (Table 4).

A change of the empirical antimicrobial treatment regimen can be considered in patients with fever recurrent or persisting for more than $96 \mathrm{~h}$; however, a general change of antibacterial agents is not recommended (DIIr). In clinical studies on antibiotic therapy of neutropenic fever, median time to defervescence was 4 to 5 days [120-122]. The empirical addition of vancomycin after non-response to piperacillin/tazobactam [121] or teicoplanin after non-response to imipenem [123] has not been more effective than placebo, and defervescence after another $72 \mathrm{~h}$ of the unmodified betalactam regimen (placebo arms) was $45 \%$. A modification or escalation of antimicrobial therapy only because of persistent elevation of inflammatory laboratory parameters has not been successful as well [70]. A change of antimicrobial therapy is recommended in patients with recurrent or persisting fever and clinical deterioration, instability, or other signs of progressive infectious disease (AIIu). In the case of severe sepsis and/or signs of critical organ failure, modification of antimicrobial therapy along with intensive further medical support is required (AIIu) [4].

As prospective studies for second-line antimicrobial therapy in neutropenic patients with persistent FUO under clearly specified 1st-line treatment regimens are sparse [124], recommendation of treatment modification are partially based on clinical expertise. 
A change of empirical antimicrobial therapy aims to cover a broader range of bacteria and/or to overcome resistance among pathogens principally included in the spectrum of the first-line regimen. Again, the local prevalence of vancomycin-resistant enterococci, methicillin-resistant $S$. aureus, and extended-spectrum beta-lactamaseproducing gram-negative bacilli, as well as the rate of primary resistance to piperacillin/tazobactam among Escherichia coli must be reconsidered (AIIt). Antimicrobial agents recommended for empirical secondline treatment are included in Table 5. In standard-risk patients initially treated with a cephalosporin plus/minus an aminoglycoside, a change to piperacillin/tazobactam, meropenem, or imipenem is recommended (AIIt).

\section{Empirical antifungal treatment in high-risk patients}

Empirical antifungal therapy is not recommended in patients of the standard-risk group (DIII). In high-risk patients, a prospective randomized trial showed a higher defervescence rate after addition of empirical mold-active antifungal therapy as compared with modification of antibacterial agents only

Table 5 Antimicrobial agents suitable for 1st- and 2nd-line therapies

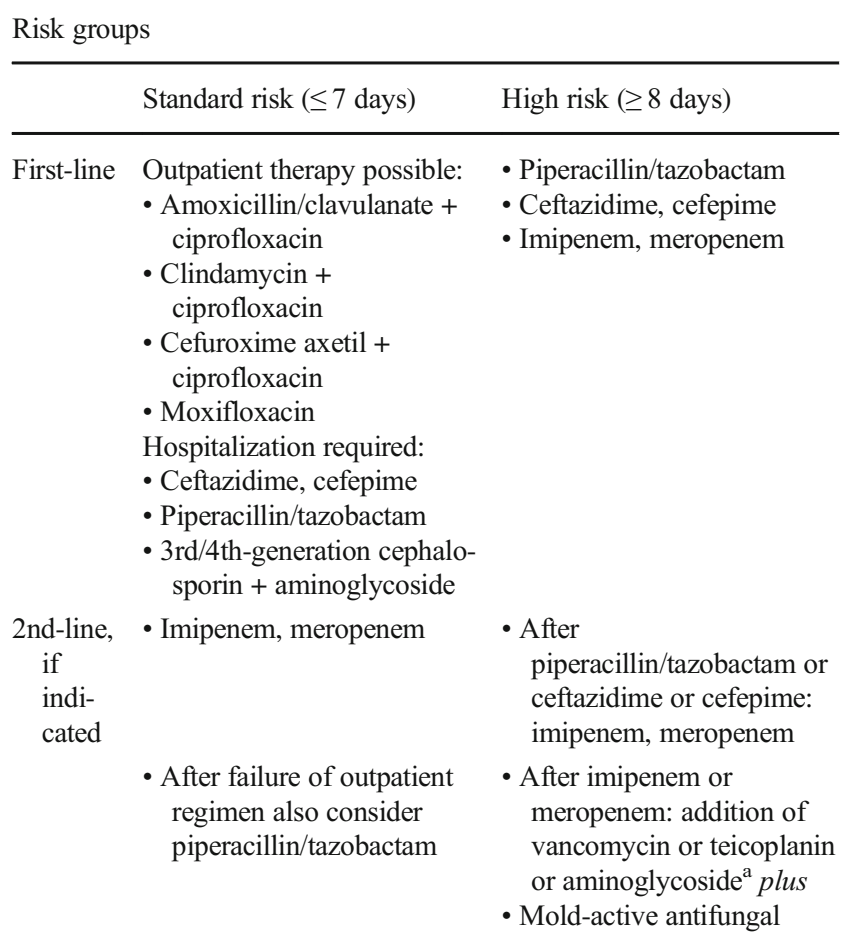

${ }^{a}$ Depending on local epidemiology and individual patient-related risk factors
[125]. These data were confirmed in a meta-analysis, yet a significant survival benefit could not be demonstrated [126, 127]. No benefit, however, could be shown for high-risk neutropenic patients, if antifungal therapy was applied already at onset of first fever instead of fever persisting for more than $72 \mathrm{~h}$ [128].

For high-risk patients without prior systemic antifungal prophylaxis, mold-active empirical antifungal therapy is recommended, if fever persists for $\geq 96 \mathrm{~h}$ or if fever relapses despite adequate antibacterial therapy (AI). This also includes patients given either oral itraconazole prophylaxis but not achieving sufficient serum or plasma trough concentrations ( $>500 \mathrm{ng} / \mathrm{ml}$ ) or a mold-inactive prophylaxis, i.e., fluconazole (BIIt). For patients receiving oral voriconazole or posaconazole prophylaxis, no prospective trial on the efficacy of a switch to another mold-active agent for empirical antifungal therapy is available. Thus, such a switch may be judicious in the setting of persistent FUO (CIII), but if a patient shows no clinical sign of invasive fungal disease despite adequate diagnostic work-up, blood samples were negative for Aspergillus galactomannan, and levels of posaconazole or voriconazole are within the target range, unmodified continuation of oral antifungal prophylaxis is reasonable. In the case of clinical deterioration, a change to an intravenously applied antifungal agent is recommended (AIII). For empirical moldactive antifungal therapy in febrile neutropenic patients, caspofungin and liposomal amphotericin $\mathrm{B}(\mathrm{AmB})$ are approved $[129,130]$. Liposomal amphotericin $B$ is preferred in patients at increased risk of fungal infection with nonAspergillus molds (AI).

Several studies have aimed at a reduction of antifungal therapy in high-risk patients by not empirically treating all patients with persisting fever in prolonged neutropenia but only those with additional findings indicating the presence of a fungal disease. Utilizing pulmonary CT scan and testing for galactomannan, Aspergillus-specific PCR or both have been used for this so-called diagnostic-driven or pre-emptive approach. An increased number of invasive fungal infections and a substantially reduced consumption of antifungals were found in the pre-emptive as compared with the empirical treatment groups, without a significant increase in mortality rates [127, 131-135]. This approach cannot be recommended as a routine standard but might provide an alternative to empirical antifungal therapy (BIIr).

Numerous studies have compared efficacy and safety of empirical antifungal treatment. The most robust data are available for caspofungin or liposomal AmB (AI) (Table 6). Conventional $\mathrm{AmB}$ deoxycholate is not recommended because of its renal toxicity and other adverse events (DI). The use of the two lipid AmB formulations ABCD and ABLC is 
Table 6 Recommendations for empirical antifungal therapy in highrisk neutropenic patients without prior Aspergillus-active antifungal prophylaxis and fever persisting for $\geq 96 \mathrm{~h}$

\begin{tabular}{lll}
\hline & Level & Evidence \\
\hline cAmB & D & I \\
ABLC & D & I \\
ABCD & D & I \\
L-AmB & A & I \\
Caspofungin & A & I \\
Itraconazole IV & $\mathrm{C}$ & I \\
Micafungin & C & I \\
Voriconazole & B & I \\
\hline
\end{tabular}

$c-A m B$ conventional amphotericin $\mathrm{B}$ (= deoxycholate $\mathrm{AmB}$ ), $A B C D$ amphotericin $\mathrm{B}$ colloidal dispersion, $A B L C$ amphotericin $\mathrm{B}$ lipid complex, $L-A m B$ liposomal amphotericin $\mathrm{B}, I V$ intravenous

not supported due to the lack of appropriate clinical studies in this setting. For voriconazole (BI), a prospective trial could not demonstrate non-inferiority to liposomal AmB in a composite endpoint, although it was associated with a lower rate of breakthrough fungal infections [136]. For itraconazole, relevant data are available for the intravenous formulation [137]. As the oral application is associated with impaired bioavailability, only the intravenous application can be recommended (BI). For micafungin (CI), a comparison with intravenous itraconazole showed superior response rates, but no study with a standard of care (caspofungin or liposomal AmB) as the comparator is available [138-141]. No data are available for anidulafungin or posaconazole in the empirical indication. Fluconazole, with no effect on mold infections, is not recommended for empirical antifungal therapy in persistently febrile neutropenic high-risk patients [125].

\section{Empirical antiviral treatment}

Empirical antiviral therapy in febrile neutropenic patients without signs or symptoms typical for a viral infection is discouraged (DIII).

\section{Adjunctive measures}

\section{Granulocyte colony-stimulating factor}

The adjunctive use if granulocyte colony-stimulating factor (G-CSF) is not recommended for routine clinical practice in febrile neutropenic patients (DIIr). If G-CSF has not been started before the onset of neutropenia, its interventional use can be considered in patients with fever and neutropenia who are at high risk for infection-associated complications or who have prognostic factors that are predictive of poor clinical outcomes, including expected prolonged ( $>10$ days) and profound $(<100 / \mu \mathrm{l})$ neutropenia, age $>65$ years, uncontrolled primary disease, or hospitalization at the time of fever development [142] (BIIr).

\section{Polyclonal immunoglobulins}

Supportive therapy with polyclonal immunoglobulin is recommended only in select neutropenic patients with proven immunoglobulin deficiency (BIIt).

\section{Removal or change of a central venous catheter and hygiene}

In a high-risk setting such as neutropenic fever, potential sources of infection should be identified and removed if possible. Central venous catheters not indispensable for patient care should be taken off. In patients with persistent FUO in whom no focus of infection has been found, empirical removal or change of the catheter may be justified (CIII).

\section{Duration of empirical antimicrobial therapy after defervescence}

The appropriate duration of antimicrobial therapy in neutropenic patients after onset of stable defervescence, i.e., body temperature below $38^{\circ} \mathrm{C}$ without the use of antipyretic drugs, has not been prospectively studied. A continuation until neutrophil recovery [143] has been questioned by results from several studies $[22,125,144,145]$ on discontinuation of parenteral antibiotics in responding, but persistently neutropenic patients, showing no substantial rates of recurrence of fever or documented infections. Challenges of antimicrobial stewardship in an era of globally increasing multidrug-resistance and missing development of new broad-spectrum anti-infectives gave reason for the recommendation to drastically shorten the administration of antibiotics in neutropenic patients after treatment response [146].

In persistently neutropenic patients, empirical therapy may be discontinued, but not earlier than 7 days after the onset of stable defervescence (without the use of antipyretic agents) and only in the absence of clinical signs or symptoms of infection (BIII). In this setting, a re-institution of systemic antibacterial prophylaxis, if given before the onset of fever, may be considered (CIII) [147]. In the case of hematopoietic recovery to a neutrophil count of $>500 / \mu 1$, empirical antimicrobial therapy can be safely discontinued after 2 days of stable defervescence [22] (BIII). 
Summary of recommendations (Tables 7, 8, 9, and 10)

Table 7 Summary of recommendations for diagnostic procedures in asymptomatic high-risk patients before onset of neutropenia

\begin{tabular}{|c|c|c|c|c|}
\hline Patient population & Intention & Intervention & $\begin{array}{l}\text { Strength of } \\
\text { recommendation }\end{array}$ & $\begin{array}{l}\text { Quality of } \\
\text { evidence }\end{array}$ \\
\hline High-risk neutropenia & Identify previous infection & Take history and perform physical examination & A & III \\
\hline High-risk neutropenia & Identify previous infection & Order chest radiograph $(2 \text { views })^{\mathrm{a}}$ & $\mathrm{C}$ & III \\
\hline High-risk neutropenia & Identify previous infection & Order abdominal ultrasound ${ }^{\mathrm{a}}$ & $\mathrm{C}$ & III \\
\hline High-risk neutropenia & Identify colonization with VRE or MRSA & $\begin{array}{l}\text { Take nasal/pharyngeal (MRSA) } \\
\text { or rectal (VRE) swabs }\end{array}$ & $\mathrm{B}$ & III \\
\hline High-risk neutropenia & Identify colonization with ESBL & Take rectal swabs & $\mathrm{B}$ & IIt \\
\hline
\end{tabular}

${ }^{\mathrm{a}}$ In patients without recent chest/abdominal CT scan performed to stage the underlying disease

Table 8 Summary of recommendations for diagnostic procedures in neutropenic patients with fever

\begin{tabular}{|c|c|c|c|c|}
\hline Patient population & Intention & Intervention & $\begin{array}{l}\text { Strength of } \\
\text { recommendation }\end{array}$ & $\begin{array}{l}\text { Quality of } \\
\text { evidence }\end{array}$ \\
\hline Febrile neutropenia & $\begin{array}{l}\text { Identify focus of } \\
\text { infection }\end{array}$ & Take history and perform physical examination & A & III \\
\hline Febrile neutropenia & $\begin{array}{l}\text { Diagnose blood } \\
\text { stream infection }\end{array}$ & $\begin{array}{l}\text { Take at least } 2 \text { separate sets of blood cultures }(\mathrm{BC}) \\
\text { prior to start of antimicrobial therapy }\end{array}$ & A & II \\
\hline $\begin{array}{l}\text { Febrile neutropenia, indwelling central } \\
\text { venous catheter (CVC) }\end{array}$ & $\begin{array}{l}\text { Diagnose CVC } \\
\text { infection }\end{array}$ & $\begin{array}{l}\text { Take at least } 1 \text { set of BC from peripheral vein and } 1 \text { set } \\
\text { of BC from CVC }\end{array}$ & A & II \\
\hline $\begin{array}{l}\text { Febrile neutropenia, no respiratory } \\
\text { symptoms }\end{array}$ & $\begin{array}{l}\text { Diagnose } \\
\text { pneumonia }\end{array}$ & Order chest radiograph & $\mathrm{D}$ & II \\
\hline $\begin{array}{l}\text { Febrile neutropenia, respiratory } \\
\text { symptoms }\end{array}$ & $\begin{array}{l}\text { Diagnose } \\
\text { pneumonia }\end{array}$ & Order thoracic CT scan & $\mathrm{B}$ & III \\
\hline Persistent $(\geq 96 \mathrm{~h})$ febrile neutropenia & $\begin{array}{l}\text { Diagnose } \\
\text { pneumonia }\end{array}$ & Order thoracic CT scan & $\mathrm{B}$ & II \\
\hline
\end{tabular}

Table 9 Summary of recommendations for antimicrobial treatment of FUO

\begin{tabular}{|c|c|c|c|c|}
\hline Patient population & Intention & Intervention & $\begin{array}{l}\text { Strength of } \\
\text { recommendation }\end{array}$ & $\begin{array}{l}\text { Quality of } \\
\text { evidence }\end{array}$ \\
\hline Febrile neutropenia & Cure & Start antibiotic therapy (ABT) within $2 \mathrm{~h}$ & A & III \\
\hline Outpatient febrile neutropenia, standard risk & Cure & $\begin{array}{l}\text { Consider oral ABT with amoxicillin/clavulanate } \\
+ \text { ciprofloxacin or with moxifloxacin }\end{array}$ & A & I \\
\hline High-risk febrile neutropenia & Cure & $\begin{array}{l}\text { Intravenous ABT with piperacillin/tazobactam, } \\
\text { imipenem, meropenem, cefepime, or ceftazidime }\end{array}$ & A & I \\
\hline $\begin{array}{l}\text { Persistent ( } \geq 96 \mathrm{~h} \text { ) high-risk febrile neutropenia, } \\
\text { no mold-active prophylaxis }\end{array}$ & Cure & $\begin{array}{l}\text { Empirical antifungal therapy with caspofungin } \\
\text { or liposomal amphotericin B }\end{array}$ & A & I \\
\hline
\end{tabular}


Table 10 Daily dosages of antimicrobial agents in adult febrile neutropenic patients without specific contraindications or renal dysfunction

\begin{tabular}{|c|c|c|}
\hline Substance & Application & Dosage \\
\hline Amoxicillin/clavulanate & Oral & $1000 \mathrm{mg}$ twice or 3 times daily \\
\hline Ciprofloxacin & Oral & $500-750 \mathrm{mg}$ twice daily \\
\hline Levofloxacin & Oral & $500 \mathrm{mg}$ twice daily \\
\hline Moxifloxacin & Oral & $400 \mathrm{mg}$ once daily \\
\hline Piperacillin/tazobactam & Intravenous & $4.5 \mathrm{~g} 3$ or 4 times daily \\
\hline Meropenem & Intravenous & 1 g 3 times daily \\
\hline Imipenem & Intravenous & $0.5-1 \mathrm{~g} 4$ times daily \\
\hline Ceftazidime & Intravenous & 2 g 3 times daily \\
\hline Cefepime & Intravenous & 2 g 3 times daily \\
\hline Gentamicin $^{\mathrm{a}}$ & Intravenous & $1.5-2.0 \mathrm{mg} / \mathrm{kg} 3$ times daily or $4.5-6.0 \mathrm{mg} / \mathrm{kg}$ once daily \\
\hline Tobramycin ${ }^{\mathrm{a}}$ & Intravenous & $1.5-2.0 \mathrm{mg} / \mathrm{kg} 3$ times daily or $5.0-6.0 \mathrm{mg} / \mathrm{kg}$ once daily \\
\hline Amikacin ${ }^{\mathrm{a}}$ & Intravenous & $7.5 \mathrm{mg} / \mathrm{kg}$ twice daily or $15 \mathrm{mg} / \mathrm{kg}$ once daily \\
\hline Vancomycin $^{\mathrm{a}}$ & Intravenous & $1 \mathrm{~g}$ twice daily \\
\hline Teicoplanin ${ }^{\mathrm{b}}$ & Intravenous & $\begin{array}{l}400 \mathrm{mg} \text { once daily with one additional loading dose } 12 \mathrm{~h} \\
\text { after the first dose }\end{array}$ \\
\hline Caspofungin & Intravenous & $70 \mathrm{mg}$ day $1,50 \mathrm{mg}$ once daily from day 2 onwards \\
\hline Liposomal amphotericin B & Intravenous & $3 \mathrm{mg} / \mathrm{kg}$ once daily \\
\hline
\end{tabular}

${ }^{\mathrm{a}}$ Therapeutic drug monitoring required

${ }^{\mathrm{b}}$ Therapeutic drug monitoring recommended in selected patients

\section{Compliance with ethical standards}

Conflict of interest DB is a consultant to Gilead Sciences and received research grants from Gilead and Pfizer, honoraria for lectures from Astellas, Gilead, MSD/Merck, TEVA, and Pfizer and travel grants from Astellas, Merck/MSD, and Pfizer. GM has been a consultant to Gilead and F2G and received honoraria for lectures from Gilead, Pfizer, Basilea, and Astellas. HL has received research grants from Amgen, Merck/MSD, Hexal, and TEVA; is a consultant to Amgen, Chugai, Grifols, Hexal, Merck/MSD, and TEVA; and received honoraria for lectures from Amgen, Hexal, Merck/MSD, and TEVA. HO received research grants from Gilead and MSD; is consultant to Astellas and MSD; and received lecture honoraria and travel grants from Astellas, Basilea, Gilead, Pfizer, and Merck/MSD. JJV has been a speaker for Astellas, Gilead, Merck/ MSD, and Pfizer; has been a consultant to Astellas, Merck/MSD, and Pfizer; has received research funding by Astellas, Gilead, Merck/MSD, and Pfizer; and has received travel grants from Astellas, Gilead, Merck/ MSD, and Pfizer. MC has been a consultant to Basilea and Merck/MSD and received travel grants and congress support (fees) from Gilead, Merck/MSD, and Basilea and honoraria for lectures from Gilead, Merck/MSD, and Basilea. MR is a consultant to Basilea and served at the speakers' bureau of Basilea. MvLT is supported by the German Federal Ministry of Research and Education (BMBF grants 01EO1002 and 13GW0096D); has received research grants from Pfizer and MSD, is a consultant to Merck/MSD; and received honoraria or travel grants from Basilea, Gilead, Merck/MSD, and Astellas. OAC is supported by the German Federal Ministry of Research and Education and the European Commission and has received research grants from, is an advisor to, or received lecture honoraria from Achaogen, Actelion, Amplyx, Anacor, Aranis, Astellas, AstraZeneca, Basilea, Bayer, Cidara, Da Volterra, F2G, Gilead, GSK, Janssen, Matinas, MedPace, Melinta, Menarini, Merck/ MSD, Miltenyi, Paratek, Pfizer, Rempex, Roche, Sanofi Pasteur, Scynexis, Seres, Summit, Tetraphase, Medicines Company, and Vical. OP received research grants from Bio-Rad and Gilead; is consultant to Merck/MSD and Gilead; and received lecture honoraria and travel grants from Astellas, Gilead, Pfizer, and Merck/MSD. SN received travel grants from Bristol-Myers Squibb, Gilead, Roche, and Sanofi. WJH received research grants from Merck/MSD and Pfizer; serves on the speakers' bureaus of Alexion, Astellas, Bristol-Myers Squibb, Chugai Pharma, Gilead, Janssen, Merck/MSD, and Pfizer; and received travel grants from Alexion, Astellas, Merck/MSD, Novartis, and Pfizer. XS received lecture honoraria from Merck/MSD and Riemser Pharma. FW, HE, MK, MS, and RM declare that they have no conflict of interest.

Open Access This article is distributed under the terms of the Creative Commons Attribution 4.0 International License (http:// creativecommons.org/licenses/by/4.0/), which permits unrestricted use, distribution, and reproduction in any medium, provided you give appropriate credit to the original author(s) and the source, provide a link to the Creative Commons license, and indicate if changes were made.

\section{References}

1. Bodey GP (1966) Infectious complications of acute leukemia. Med Times 94(9):1076-1085

2. Kuderer NM, Dale DC, Crawford J, Cosler LE, Lyman GH (2006) Mortality, morbidity, and cost associated with febrile neutropenia in adult cancer patients. Cancer 106(10):2258-2266. doi:10.1002/ cncr. 21847

3. Link H, Böhme A, Cornely OA, Höffken K, Kellner O, Kern WV, Mahlberg R, Maschmeyer G, Nowrousian MR, Ostermann H, Ruhnke M, Sezer O, Schiel X, Wilhelm M, Auner HW (2003) Antimicrobial therapy of unexplained fever in neutropenic patients - guidelines of the Infectious Diseases Working Party (AGIHO) of the German Society of Hematology and Oncology (DGHO), Study Group Interventional Therapy of Unexplained Fever, Arbeitsgemeinschaft Supportivmassnahmen in der Onkologie (ASO) of the Deutsche Krebsgesellschaft (DKGGerman Cancer Society). Ann Hematol 82(Suppl 2):S105-S117. doi:10.1007/s00277-003-0764-4

4. Penack O, Becker C, Buchheidt D, Christopeit M, Kiehl M, von Lilienfeld-Toal M, Hentrich M, Reinwald M, Salwender H, Schalk E, Schmidt-Hieber M, Weber T, Ostermann H (2014) Management of sepsis in neutropenic patients: 2014 updated 
guidelines from the Infectious Diseases Working Party of the German Society of hematology and medical oncology (AGIHO). Ann Hematol 93(7):1083-1095. doi:10.1007/s00277-014-2086-0

5. Neumann S, Krause SW, Maschmeyer G, Schiel X, von Lilienfeld-Toal M (2013) Primary prophylaxis of bacterial infections and Pneumocystis jirovecii pneumonia in patients with hematological malignancies and solid tumors: guidelines of the Infectious Diseases Working Party (AGIHO) of the German Society of Hematology and Oncology (DGHO). Ann Hematol 92(4):433-442. doi:10.1007/s00277-013-1698-0

6. Tacke D, Buchheidt D, Karthaus M, Krause SW, Maschmeyer G, Neumann S, Ostermann H, Penack O, Rieger C, Ruhnke M, Sandherr M, Schweer KE, Ullmann AJ, Cornely OA (2014) Primary prophylaxis of invasive fungal infections in patients with haematologic malignancies. 2014 update of the recommendations of the Infectious Diseases Working Party of the German Society for Haematology and Oncology. Ann Hematol 93(9):1449-1456. doi:10.1007/s00277-014-2108-y

7. Ullmann AJ, Schmidt-Hieber M, Bertz H, Heinz WJ, Kiehl M, Kruger W, Mousset S, Neuburger S, Neumann S, Penack O, Silling G, Vehreschild JJ, Einsele H, Maschmeyer G (2016) Infectious diseases in allogeneic haematopoietic stem cell transplantation: prevention and prophylaxis strategy guidelines 2016 . Ann Hematol 95(9):1435-1455. doi:10.1007/s00277-016-2711-1

8. Ruhnke M, Böhme A, Buchheidt D, Cornely O, Donhuijsen K, Einsele H, Enzensberger R, Hebart H, Heussel CP, Horger M, Hof H, Karthaus M, Kruger W, Maschmeyer G, Penack O, Ritter J, Schwartz S (2012) Diagnosis of invasive fungal infections in hematology and oncology - guidelines from the Infectious Diseases Working Party in Haematology and Oncology of the German Society for Haematology and Oncology (AGIHO). Ann Oncol 23(4):823-833. doi:10.1093/annonc/mdr407

9. Mousset S, Buchheidt D, Heinz W, Ruhnke M, Cornely O, Egerer G, Krüger W, Link H, Neumann S, Ostermann H, Panse J, Penack O, Rieger C, Schmidt-Hieber M, Silling G, Südhoff T, Ullmann A, Wolf H-H, Maschmeyer G, Böhme A (2013) Treatment of invasive fungal infections in cancer patients - updated recommendations of the Infectious Diseases Working Party (AGIHO) of the German Society of Hematology and Oncology (DGHO). Ann Hematol 93:13-32. doi:10.1007/s00277-013-1867-1

10. Maschmeyer G, Carratala J, Buchheidt D, Hamprecht A, Heussel CP, Kahl C, Lorenz J, Neumann S, Rieger C, Ruhnke M, Salwender H, Schmidt-Hieber M, Azoulay E, Infectious Diseases Working Party of the German Society of Hematology and Medical Oncology (2015) Diagnosis and antimicrobial therapy of lung infiltrates in febrile neutropenic patients (allogeneic SCT excluded): updated guidelines of the Infectious Diseases Working Party (AGIHO) of the German Society of Hematology and Medical Oncology (DGHO). Ann Oncol 26(1):21-33. doi:10. 1093/annonc/mdu192

11. Vehreschild MJ, Vehreschild JJ, Hubel K, Hentrich M, SchmidtHieber M, Christopeit M, Maschmeyer G, Schalk E, Cornely OA, Neumann S (2013) Diagnosis and management of gastrointestinal complications in adult cancer patients: evidence-based guidelines of the Infectious Diseases Working Party (AGIHO) of the German Society of Hematology and Oncology (DGHO). Ann Oncol 24(5): 1189-1202. doi:10.1093/annonc/mdt001

12. Hentrich M, Schalk E, Schmidt-Hieber M, Chaberny I, Mousset S, Buchheidt D, Ruhnke M, Penack O, Salwender H, Wolf HH, Christopeit M, Neumann S, Maschmeyer G, Karthaus M, Infectious Diseases Working Party of the German Society of Hematology and Medical Oncology (2014) Central venous catheter-related infections in hematology and oncology: 2012 updated guidelines on diagnosis, management and prevention by the Infectious Diseases Working Party of the German Society of
Hematology and Medical Oncology. Ann Oncol 25(5):936-947. doi:10.1093/annonc/mdt545

13. Schmidt-Hieber M, Silling G, Schalk E, Heinz W, Panse J, Penack O, Christopeit M, Buchheidt D, Meyding-Lamade U, Hahnel S, Wolf HH, Ruhnke M, Schwartz S, Maschmeyer G (2016) CNS infections in patients with hematological disorders (including allogeneic stem-cell transplantation) - guidelines of the Infectious Diseases Working Party (AGIHO) of the German Society of Hematology and Medical Oncology (DGHO). Ann Oncol 27(7): 1207-1225. doi:10.1093/annonc/mdw155

14. Weissinger F, Auner HW, Bertz H, Buchheidt D, Cornely OA, Egerer G, Heinz W, Karthaus M, Kiehl M, Kruger W, Penack O, Reuter S, Ruhnke M, Sandherr M, Salwender HJ, Ullmann AJ, Waldschmidt DT, Wolf HH (2012) Antimicrobial therapy of febrile complications after high-dose chemotherapy and autologous hematopoietic stem cell transplantation-guidelines of the Infectious Diseases Working Party (AGIHO) of the German Society of Hematology and Oncology (DGHO). Ann Hematol 91(8):1161-1174. doi:10.1007/s00277-012-1456-8

15. von Lilienfeld-Toal M, Berger A, Christopeit M, Hentrich M, Heussel CP, Kalkreuth J, Klein M, Kochanek M, Penack O, Hauf E, Rieger C, Silling G, Vehreschild M, Weber T, Wolf HH, Lehners N, Schalk E, Mayer K (2016) Community acquired respiratory virus infections in cancer patients - guideline on diagnosis and management by the Infectious Diseases Working Party of the German Society for Haematology and Medical Oncology. Eur J Cancer (Oxf, Engl: 1990) 67:200-212. doi:10.1016/j.ejca.2016. 08.015

16. Ullmann AJ, Akova M, Herbrecht R, Viscoli C, Arendrup MC, Arikan-Akdagli S, Bassetti M, Bille J, Calandra T, Castagnola E, Cornely OA, Donnelly JP, Garbino J, Groll AH, Hope WW, Jensen HE, Kullberg BJ, Lass-Florl C, Lortholary O, Meersseman W, Petrikkos G, Richardson MD, Roilides E, Verweij PE, Cuenca-Estrella M (2012) ESCMID* guideline for the diagnosis and management of Candida diseases 2012: adults with haematological malignancies and after haematopoietic stem cell transplantation (HCT). Clin Microbiol Infect 18(Suppl 7):5367. doi:10.1111/1469-0691.12041

17. Klastersky J, Paesmans M, Rubenstein EB, Boyer M, Elting L, Feld R, Gallagher J, Herrstedt J, Rapoport B, Rolston K, Talcott J (2000) The Multinational Association for Supportive Care in Cancer risk index: a multinational scoring system for identifying low-risk febrile neutropenic cancer patients. J Clin Oncol 18(16): 3038-3051. doi:10.1200/jco.2000.18.16.3038

18. Kern WV, Cometta A, De Bock R, Langenaeken J, Paesmans M, Gaya H (1999) Oral versus intravenous empirical antimicrobial therapy for fever in patients with granulocytopenia who are receiving cancer chemotherapy. International Antimicrobial Therapy Cooperative Group of the European Organization for Research and Treatment of Cancer. N Engl J Med 341(5):312-318. doi: 10.1056/nejm199907293410502

19. Kern WV, Marchetti O, Drgona L, Akan H, Aoun M, Akova M, de Bock R, Paesmans M, Viscoli C, Calandra T (2013) Oral antibiotics for fever in low-risk neutropenic patients with cancer: a double-blind, randomized, multicenter trial comparing single daily moxifloxacin with twice daily ciprofloxacin plus amoxicillin/ clavulanic acid combination therapy-EORTC infectious diseases group trial XV. J Clin Oncol 31(9):1149-1156. doi:10.1200/jco. 2012.45.8109

20. Nakagawa Y, Suzuki K, Masaoka T (2009) Evaluation of the risk factors for febrile neutropenia associated with hematological malignancy. J Infect Chemother 15(3):174-179. doi:10.1007/ s10156-009-0683-y

21. Cherif H, Johansson E, Björkholm M, Kalin M (2006) The feasibility of early hospital discharge with oral antimicrobial therapy in 
low risk patients with febrile neutropenia following chemotherapy for hematologic malignancies. Haematologica 91(2):215-222

22. Link H, Maschmeyer G, Meyer P, Hiddemann W, Stille W, Helmerking M, Adam D (1994) Interventional antimicrobial therapy in febrile neutropenic patients. Study Group of the Paul Ehrlich Society for Chemotherapy. Ann Hematol 69(5):231-243

23. Elting LS, Rubenstein EB, Rolston KV, Bodey GP (1997) Outcomes of bacteremia in patients with cancer and neutropenia: observations from two decades of epidemiological and clinical trials. Clin Infect Dis 25(2):247-259

24. Wisplinghoff H, Cornely OA, Moser S, Bethe U, Stutzer H, Salzberger B, Fatkenheuer G, Seifert H (2003) Outcomes of nosocomial bloodstream infections in adult neutropenic patients: a prospective cohort and matched case-control study. Infect Control Hosp Epidemiol 24(12):905-911. doi:10.1086/502158

25. Kirchhoff LV, Sheagren JN (1985) Epidemiology and clinical significance of blood cultures positive for coagulase-negative staphylococcus. Infect Control: IC 6(12):479-486

26. Pagano L, Caira M, Candoni A, Offidani M, Fianchi L, Martino B, Pastore D, Picardi M, Bonini A, Chierichini A, Fanci R, Caramatti C, Invernizzi R, Mattei D, Mitra ME, Melillo L, Aversa F, Van Lint MT, Falcucci P, Valentini CG, Girmenia C, Nosari A (2006) The epidemiology of fungal infections in patients with hematologic malignancies: the SEIFEM-2004 study. Haematologica 91(8): 1068-1075

27. Kern WV, Klose K, Jellen-Ritter AS, Oethinger M, Bohnert J, Kern P, Reuter S, von Baum H, Marre R (2005) Fluoroquinolone resistance of Escherichia coli at a cancer center: epidemiologic evolution and effects of discontinuing prophylactic fluoroquinolone use in neutropenic patients with leukemia. Eur $\mathrm{J}$ Clin Microbiol Infect Dis 24(2):111-118. doi:10.1007/s10096005-1278-x

28. Kern WV, Andriof E, Oethinger M, Kern P, Hacker J, Marre R (1994) Emergence of fluoroquinolone-resistant Escherichia coli at a cancer center. Antimicrob Agents Chemother 38(4):681-687

29. Ruhnke M, Arnold R, Gastmeier P (2014) Infection control issues in patients with haematological malignancies in the era of multidrug-resistant bacteria. Lancet Oncol 15(13):e606-e619. doi:10.1016/s1470-2045(14)70344-4

30. Saito T, Yoshioka S, Iinuma Y, Takakura S, Fujihara N, Ichinohe T, Ishikawa T, Uchiyama T, Ichiyama S (2008) Effects on spectrum and susceptibility patterns of isolates causing bloodstream infection by restriction of fluoroquinolone prophylaxis in a hematology-oncology unit. Eur J Clin Microbiol Infect Dis 27(3):209-216. doi:10.1007/s10096-007-0428-8

31. Bossaer JB, Hall PD, Garrett-Mayer E (2010) Incidence of vancomycin-resistant enterococci (VRE) infection in high-risk febrile neutropenic patients colonized with VRE. Support Care Cancer 19(2):231-237. doi:10.1007/s00520-009-0808-y

32. Matar MJ, Safdar A, Rolston KV (2006) Relationship of colonization with vancomycin-resistant enterococci and risk of systemic infection in patients with cancer. Clin Infect Dis 42(10):15061507. doi:10.1086/503675

33. Charbonneau P, Parienti JJ, Thibon P, Ramakers M, Daubin C, du Cheyron D, Lebouvier G, Le Coutour X, Leclercq R (2006) Fluoroquinolone use and methicillin-resistant Staphylococcus aureus isolation rates in hospitalized patients: a quasi experimental study. Clin Infect Dis 42(6):778-784. doi:10.1086/500319

34. Linder JA, Huang ES, Steinman MA, Gonzales R, Stafford RS (2005) Fluoroquinolone prescribing in the United States: 1995 to 2002. Am J Med 118(3):259-268. doi:10.1016/j.amjmed.2004. 09.015

35. Goossens H, Ferech M, Vander Stichele R, Elseviers M (2005) Outpatient antibiotic use in Europe and association with resistance: a cross-national database study. Lancet (Lond, Engl) 365(9459):579-587. doi:10.1016/s0140-6736(05)17907-0
36. Liss BJ, Vehreschild JJ, Cornely OA, Hallek M, Fätkenheuer G, Wisplinghoff H, Seifert H, Vehreschild MJGT (2012) Intestinal colonisation and blood stream infections due to vancomycinresistant enterococci (VRE) and extended-spectrum betalactamase-producing Enterobacteriaceae (ESBLE) in patients with haematological and oncological malignancies. Infection 40(6): 613-619. doi:10.1007/s15010-012-0269-y

37. Cumpston A, Craig M, Hamadani M, Abraham J, Hobbs GR, Sarwari AR (2013) Extended follow-up of an antibiotic cycling program for the management of febrile neutropenia in a hematologic malignancy and hematopoietic cell transplantation unit. Transpl Infect Dis 15(2):142-149. doi:10.1111/tid.12035

38. Vehreschild MJ, Hamprecht A, Peterson L, Schubert S, Hantschel M, Peter S, Schafhausen P, Rohde H, Lilienfeld-Toal MV, Bekeredjian-Ding I, Libam J, Hellmich M, Vehreschild JJ, Cornely OA, Seifert H (2014) A multicentre cohort study on colonization and infection with ESBL-producing Enterobacteriaceae in high-risk patients with haematological malignancies. J Antimicrob Chemother 69(12):3387-3392. doi:10.1093/jac/ dku305

39. Ng ES, Liew Y, Koh LP, Hsu LY (2010) Fluoroquinolone prophylaxis against febrile neutropenia in areas with high fluoroquinolone resistance - an Asian perspective. J Formos Med Assoc 109(9):624-631. doi:10.1016/s0929-6646(10)60102-7

40. Jones BM, Bland CM (2017) Penicillin skin testing as an antimicrobial stewardship initiative. Am J Health Syst Pharm 74(4):232 237. doi:10.2146/ajhp160233

41. Macy E, Khan DA, Castells MC, Lang DM (2017) Penicillin allergy testing: a key component of antibiotic stewardship. Clin Infect Dis 64(4):531-532. doi:10.1093/cid/ciw795

42. Rimawi RH, Cook PP, Gooch M, Kabchi B, Ashraf MS, Rimawi BH, Gebregziabher M, Siraj DS (2013) The impact of penicillin skin testing on clinical practice and antimicrobial stewardship. J Hosp Med 8(6):341-345. doi:10.1002/jhm.2036

43. Maertens J, Theunissen K, Verbeken E, Lagrou K, Verhaegen J, Boogaerts M, Eldere JV (2004) Prospective clinical evaluation of lower cut-offs for galactomannan detection in adult neutropenic cancer patients and haematological stem cell transplant recipients. Br J Haematol 126(6):852-860. doi:10.1111/j.1365-2141.2004. 05140.x

44. Maertens J, Verhaegen J, Lagrou K, Van Eldere J, Boogaerts M (2001) Screening for circulating galactomannan as a noninvasive diagnostic tool for invasive aspergillosis in prolonged neutropenic patients and stem cell transplantation recipients: a prospective validation. Blood 97(6):1604-1610

45. Pazos C, Ponton J, Del Palacio A (2005) Contribution of (1->3)beta-D-glucan chromogenic assay to diagnosis and therapeutic monitoring of invasive aspergillosis in neutropenic adult patients: a comparison with serial screening for circulating galactomannan. J Clin Microbiol 43(1):299-305. doi:10.1128/jcm.43.1.299-305. 2005

46. Senn L, Robinson JO, Schmidt S, Knaup M, Asahi N, Satomura S, Matsuura S, Duvoisin B, Bille J, Calandra T, Marchetti O (2008) 1,3-Beta-D-glucan antigenemia for early diagnosis of invasive fungal infections in neutropenic patients with acute leukemia. Clin Infect Dis 46(6):878-885. doi:10.1086/527382

47. Mengoli C, Cruciani M, Barnes RA, Loeffler J, Donnelly JP (2009) Use of PCR for diagnosis of invasive aspergillosis: systematic review and meta-analysis. Lancet Infect Dis 9(2):89-96. doi: 10.1016/s1473-3099(09)70019-2

48. Marr KA, Laverdiere M, Gugel A, Leisenring W (2005) Antifungal therapy decreases sensitivity of the Aspergillus galactomannan enzyme immunoassay. Clin Infect Dis 40(12): 1762-1769. doi:10.1086/429921

49. Reinwald M, Hummel M, Kovalevskaya E, Spiess B, Heinz WJ, Vehreschild JJ, Schultheis B, Krause SW, Claus B, Suedhoff T, 
Schwerdtfeger R, Reuter S, Kiehl MG, Hofmann WK, Buchheidt D (2012) Therapy with antifungals decreases the diagnostic performance of PCR for diagnosing invasive aspergillosis in bronchoalveolar lavage samples of patients with haematological malignancies. J Antimicrob Chemother 67(9):2260-2267. doi:10. 1093/jac/dks208

50. Ferrer R, Martin-Loeches I, Phillips G, Osborn TM, Townsend S, Dellinger RP, Artigas A, Schorr C, Levy MM (2014) Empiric antibiotic treatment reduces mortality in severe sepsis and septic shock from the first hour: results from a guideline-based performance improvement program. Crit Care Med 42(8):1749-1755. doi: $10.1097 / \mathrm{ccm} .000000000000330$

51. Kumar A, Roberts D, Wood KE, Light B, Parrillo JE, Sharma S, Suppes R, Feinstein D, Zanotti S, Taiberg L, Gurka D, Kumar A, Cheang M (2006) Duration of hypotension before initiation of effective antimicrobial therapy is the critical determinant of survival in human septic shock. Crit Care Med 34(6):1589-1596. doi: 10.1097/01.ccm.0000217961.75225.e9

52. Legrand M, Max A, Peigne V, Mariotte E, Canet E, Debrumetz A, Lemiale V, Seguin A, Darmon M, Schlemmer B, Azoulay E (2012) Survival in neutropenic patients with severe sepsis or septic shock. Crit Care Med 40(1):43-49. doi:10.1097/CCM. 0b013e31822b50c2

53. Perron T, Emara M, Ahmed S (2014) Time to antibiotics and outcomes in cancer patients with febrile neutropenia. BMC Health Serv Res 14:162. doi:10.1186/1472-6963-14-162

54. Lee A, Mirrett S, Reller LB, Weinstein MP (2007) Detection of bloodstream infections in adults: how many blood cultures are needed? J Clin Microbiol 45(11):3546-3548. doi:10.1128/jcm. 01555-07

55. Cockerill FR 3rd, Wilson JW, Vetter EA, Goodman KM, Torgerson CA, Harmsen WS, Schleck CD, Ilstrup DM, Washington JA 2nd, Wilson WR (2004) Optimal testing parameters for blood cultures. Clin Infect Dis 38(12):1724-1730. doi:10. 1086/421087

56. Guembe M, Rodriguez-Creixems M, Sanchez-Carrillo C, PerezParra A, Martin-Rabadan P, Bouza E (2010) How many lumens should be cultured in the conservative diagnosis of catheter-related bloodstream infections? Clin Infect Dis 50(12):1575-1579. doi: $10.1086 / 652766$

57. Blot F, Nitenberg G, Chachaty E, Raynard B, Germann N, Antoun S, Laplanche A, Brun-Buisson C, Tancrede C (1999) Diagnosis of catheter-related bacteraemia: a prospective comparison of the time to positivity of hub-blood versus peripheral-blood cultures. Lancet (Lond, Engl) 354(9184):1071-1077

58. Seifert H, Cornely O, Seggewiss K, Decker M, Stefanik D, Wisplinghoff H, Fätkenheuer G (2003) Bloodstream infection in neutropenic cancer patients related to short-term nontunnelled catheters determined by quantitative blood cultures, differential time to positivity, and molecular epidemiological typing with pulsed-field gel electrophoresis. J Clin Microbiol 41(1):118-123

59. Tissari P, Zumla A, Tarkka E, Mero S, Savolainen L, Vaara M, Aittakorpi A, Laakso S, Lindfors M, Piiparinen H, Maki M, Carder C, Huggett J, Gant V (2010) Accurate and rapid identification of bacterial species from positive blood cultures with a DNA-based microarray platform: an observational study. Lancet (Lond, Engl) 375(9710):224-230. doi:10.1016/s0140-6736(09) 61569-5

60. von Lilienfeld-Toal M, Lehmann LE, Raadts AD, Hahn-Ast C, Orlopp KS, Marklein G, Purr I, Cook G, Hoeft A, Glasmacher A, Stuber F (2009) Utility of a commercially available multiplex real-time PCR assay to detect bacterial and fungal pathogens in febrile neutropenia. J Clin Microbiol 47(8):2405-2410. doi:10. 1128/jcm.00491-09
61. Mancini N, Clerici D, Diotti R, Perotti M, Ghidoli N, De Marco D, Pizzorno B, Emrich T, Burioni R, Ciceri F, Clementi M (2008) Molecular diagnosis of sepsis in neutropenic patients with haematological malignancies. J Med Microbiol 57(Pt 5):601-604. doi: 10.1099/jmm.0.47732-0

62. Guido M, Quattrocchi M, Zizza A, Pasanisi G, Pavone V, Lobreglio G, Gabutti G, De Donno A (2012) Molecular approaches in the diagnosis of sepsis in neutropenic patients with haematological malignances. J Prev Med Hyg 53(2):104-108

63. Desmet S, Maertens J, Bueselinck K, Lagrou K (2016) Broadrange PCR coupled with electrospray ionization time of flight mass spectrometry for detection of bacteremia and Fungemia in patients with neutropenic fever. J Clin Microbiol 54(10):25132520. doi:10.1128/jcm.01066-16

64. Lamoth F, Jaton K, Prod'hom G, Senn L, Bille J, Calandra T, Marchetti O (2010) Multiplex blood PCR in combination with blood cultures for improvement of microbiological documentation of infection in febrile neutropenia. J Clin Microbiol 48(10):3510 3516. doi: $10.1128 / \mathrm{jcm} .00147-10$

65. von Lilienfeld-Toal M, Dietrich MP, Glasmacher A, Lehmann L, Breig P, Hahn C, Schmidt-Wolf IG, Märklein G, Schroeder S, Stuber F (2004) Markers of bacteremia in febrile neutropenic patients with hematological malignancies: procalcitonin and IL-6 are more reliable than C-reactive protein. Eur J Clin Microbiol Infect Dis 23(7):539-544. doi:10.1007/s10096-004-1156-y

66. Persson L, Soderquist B, Engervall P, Vikerfors T, Hansson LO, Tidefelt U (2005) Assessment of systemic inflammation markers to differentiate a stable from a deteriorating clinical course in patients with febrile neutropenia. Eur J Haematol 74(4):297-303. doi:10.1111/j.1600-0609.2004.00387.x

67. de Bont ES, Vellenga E, Swaanenburg JC, Fidler V, Visser-van Brummen PJ, Kamps WA (1999) Plasma IL-8 and IL-6 levels can be used to define a group with low risk of septicaemia among cancer patients with fever and neutropenia. Br J Haematol 107(2):375-380

68. Prat C, Sancho JM, Dominguez J, Xicoy B, Gimenez M, Ferra C, Blanco S, Lacoma A, Ribera JM, Ausina V (2008) Evaluation of procalcitonin, neopterin, C-reactive protein, IL-6 and IL-8 as a diagnostic marker of infection in patients with febrile neutropenia. Leuk \& Lymphoma 49(9):1752-1761. doi:10.1080/ 10428190802258956

69. Steinmetz HT, Herbertz A, Bertram M, Diehl V (1995) Increase in interleukin-6 serum level preceding fever in granulocytopenia and correlation with death from sepsis. J Infect Dis 171(1):225-228

70. Wu CW, Wu JY, Chen CK, Huang SL, Hsu SC, Lee MT, Chang SS, Lee CC (2015) Does procalcitonin, C-reactive protein, or interleukin- 6 test have a role in the diagnosis of severe infection in patients with febrile neutropenia? A systematic review and meta-analysis. Support Care Cancer 23(10):2863-2872. doi:10.1007/ s00520-015-2650-8

71. Korones DN (2004) Is routine chest radiography necessary for the initial evaluation of fever in neutropenic children with cancer? Pediatr Blood Cancer 43(7):715-717. doi:10.1002/pbc.20226

72. Navigante AH, Cerchietti LC, Costantini P, Salgado H, Castro MA, Lutteral MA, Cabalar ME (2002) Conventional chest radiography in the initial assessment of adult cancer patients with fever and neutropenia. Cancer Control 9(4):346-351

73. Oude Nijhuis CS, Gietema JA, Vellenga E, Daenen SM, De Bont ES, Kamps WA, Groen HJ, van der Jagt EJ, van der Graaf WT (2003) Routine radiography does not have a role in the diagnostic evaluation of ambulatory adult febrile neutropenic cancer patients. Eur J Cancer (Oxf, Engl: 1990) 39(17):2495-2498

74. Talbot GH, Huang A, Provencher M (1991) Invasive Aspergillus rhinosinusitis in patients with acute leukemia. Rev Infect Dis 13(2):219-232 
75. Camus V, Edet-Sanson A, Bubenheim M, Hitzel A, Becker S, David M, Stamatoullas A, Lenain P, Jardin F, Contentin N, Fontoura ML, Cardinael N, Vaudaux S, Dubois S, Tilly H, Vera P, Lepretre S (2015) (1)(8)F-FDG-PET/CT imaging in patients with febrile neutropenia and Haematological malignancies. Anticancer Res 35(5):2999-3005

76. Gafter-Gvili A, Paul M, Bernstine H, Vidal L, Ram R, Raanani P, Yeshurun M, Tadmor B, Leibovici L, Shpilberg O, Groshar D (2013) The role of (1)(8)F-FDG PET/CT for the diagnosis of infections in patients with hematological malignancies and persistent febrile neutropenia. Leuk Res 37(9):1057-1062. doi:10.1016/ j.leukres.2013.06.025

77. Guy SD, Tramontana AR, Worth LJ, Lau E, Hicks RJ, Seymour JF, Thursky KA, Slavin MA (2012) Use of FDG PET/CT for investigation of febrile neutropenia: evaluation in high-risk cancer patients. Eur J Nucl Med Mol Imaging 39(8):1348-1355. doi:10. 1007/s00259-012-2143-7

78. Vos FJ, Donnelly JP, Oyen WJ, Kullberg BJ, Bleeker-Rovers CP, Blijlevens NM (2012) 18F-FDG PET/CT for diagnosing infectious complications in patients with severe neutropenia after intensive chemotherapy for haematological malignancy or stem cell transplantation. Eur J Nucl Med Mol Imaging 39(1):120-128. doi:10.1007/s00259-011-1939-1

79. Bavaro MF (2002) Neutropenic enterocolitis. Curr Gastroenterol Rep 4(4):297-301

80. Gorschlüter M, Mey U, Strehl J, Ziske C, Schepke M, SchmidtWolf IG, Sauerbruch T, Glasmacher A (2005) Neutropenic enterocolitis in adults: systematic analysis of evidence quality. Eur J Haematol 75(1):1-13. doi:10.1111/j.1600-0609.2005.00442.x

81. van Vliet M, Potting CM, Sturm PD, Donnelly JP, Blijlevens NM (2011) How prompt is prompt in daily practice? Earlier initiation of empirical antibacterial therapy for the febrile neutropenic patient. Eur J Cancer Care 20(5):679-685. doi:10.1111/j.1365-2354. 2011.01264.x

82. Yahav D, Paul M, Fraser A, Sarid N, Leibovici L (2007) Efficacy and safety of cefepime: a systematic review and meta-analysis. Lancet Infect Dis 7(5):338-348. doi:10.1016/s1473-3099(07) 70109-3

83. Kim PW, Wu YT, Cooper C, Rochester G, Valappil T, Wang Y, Kornegay C, Nambiar S (2010) Meta-analysis of a possible signal of increased mortality associated with cefepime use. Clin Infect Dis 51(4):381-389. doi:10.1086/655131

84. Research UFaDACfDEa (2009) Statistical review and evaluation. Clinical studies NDA number 50-679. Drug name: Maxipime 04/ 22/2009

85. McCullough BJ, Wiggins LE, Richards A, Klinker K, Hiemenz JW, Wingard JR (2014) Aztreonam for febrile neutropenia in patients with beta-lactam allergy. Transpl Infect Dis 16(1):145-152. doi:10.1111/tid.12148

86. Raad II, Whimbey EE, Rolston KV, Abi-Said D, Hachem RY, Pandya RG, Ghaddar HM, Karl CL, Bodey GP (1996) A comparison of aztreonam plus vancomycin and imipenem plus vancomycin as initial therapy for febrile neutropenic cancer patients. Cancer 77(7):1386-1394. doi:10.1002/(sici)10970142(19960401)77:7<1386::aid-cncr25>3.0.co;2-x

87. Nesher L, Tverdek FP, Mahajan SN, Chemaly RF, Rolston KV (2015) Ertapenem usage in cancer patients with and without neutropenia: a report on 97 cases from a comprehensive cancer center. Infection 43(5):545-550. doi:10.1007/s15010-015-0784-8

88. Toya T, Nannya Y, Narukawa K, Ichikawa M, Kurokawa M (2012) A comparative analysis of meropenem and doripenem in febrile patients with hematologic malignancies: a single-center retrospective study. Jpn J Infect Dis 65(3):228-232

89. Hachem R, Reitzel R, Rolston K, Chaftari AM, Raad I (2017) Antimicrobial activities of ceftazidime-avibactam and comparator agents against clinical bacteria isolated from patients with cancer. Antimicrob Agents Chemother 61 (4). doi:10.1128/aac.02106-16

90. Aitken SL, Kontoyiannis DP, DePombo AM, Bhatti MM, Tverdek FP, Gettys SC, Nicolau DP, Nunez CA (2016) Use of Ceftolozane/Tazobactam in the treatment of multidrug-resistant Pseudomonas aeruginosa bloodstream infection in a pediatric leukemia patient. Pediatr Infect Dis J 35(9):1040-1042. doi:10.1097/ inf.0000000000001228

91. Nakane T, Tamura K, Hino M, Tamaki T, Yoshida I, Fukushima T, Tatsumi Y, Nakagawa Y, Hatanaka K, Takahashi T, Akiyama N, Tanimoto M, Ohyashiki K, Urabe A, Masaoka T, Kanamaru A (2015) Cefozopran, meropenem, or imipenem-cilastatin compared with cefepime as empirical therapy in febrile neutropenic adult patients: a multicenter prospective randomized trial. J Infect Chemother 21(1):16-22. doi:10.1016/j.jiac.2014.08.026

92. Bucaneve G, Micozzi A, Picardi M, Ballanti S, Cascavilla N, Salutari P, Specchia G, Fanci R, Luppi M, Cudillo L, Cantaffa R, Milone G, Bocchia M, Martinelli G, Offidani M, Chierichini A, Fabbiano F, Quarta G, Primon V, Martino B, Manna A, Zuffa E, Ferrari A, Gentile G, Foa R, Del Favero A (2014) Results of a multicenter, controlled, randomized clinical trial evaluating the combination of piperacillin/tazobactam and tigecycline in highrisk hematologic patients with cancer with febrile neutropenia. J Clin Oncol 32(14):1463-1471. doi:10.1200/jco.2013.51.6963

93. Schwab KS, Hahn-Ast C, Heinz WJ, Germing U, Egerer G, Glasmacher A, Leyendecker C, Märklein G, Nellessen CM, Brossart P, von Lilienfeld-Toal M (2014) Tigecycline in febrile neutropenic patients with haematological malignancies: a retrospective case documentation in four university hospitals. Infection 42(1):97-104. doi:10.1007/s15010-013-0524-x

94. Paul M, Yahav D, Bivas A, Fraser A, Leibovici L (2010) Antipseudomonal beta-lactams for the initial, empirical, treatment of febrile neutropenia: comparison of beta-lactams. Cochrane Database Syst Rev 11:CD005197. doi:10.1002/14651858. CD005197.pub3

95. Tamma PD, Cosgrove SE, Maragakis LL (2012) Combination therapy for treatment of infections with gram-negative bacteria. Clin Microbiol Rev 25(3):450-470. doi:10.1128/cmr.05041-11

96. Furno P, Bucaneve G, Del Favero A (2002) Monotherapy or aminoglycoside-containing combinations for empirical antibiotic treatment of febrile neutropenic patients: a meta-analysis. Lancet Infect Dis 2(4):231-242

97. Paul M, Soares-Weiser K, Grozinsky S, Leibovici L (2003) Betalactam versus beta-lactam-aminoglycoside combination therapy in cancer patients with neutropaenia. Cochrane Database Syst Rev 3: CD003038. doi:10.1002/14651858.cd003038

98. Marcus R, Paul M, Elphick H, Leibovici L (2011) Clinical implications of beta-lactam-aminoglycoside synergism: systematic review of randomised trials. Int J Antimicrob Agents 37(6):491503. doi:10.1016/j.ijantimicag.2010.11.029

99. Mavros MN, Polyzos KA, Rafailidis PI, Falagas ME (2011) Once versus multiple daily dosing of aminoglycosides for patients with febrile neutropenia: a systematic review and meta-analysis. J Antimicrob Chemother 66(2):251-259. doi:10.1093/jac/dkq451

100. Vardakas KZ, Samonis G, Chrysanthopoulou SA, Bliziotis IA, Falagas ME (2005) Role of glycopeptides as part of initial empirical treatment of febrile neutropenic patients: a meta-analysis of randomised controlled trials. Lancet Infect Dis 5(7):431-439. doi: 10.1016/s1473-3099(05)70164-x

101. Zaas AK, Song X, Tucker P, Perl TM (2002) Risk factors for development of vancomycin-resistant enterococcal bloodstream infection in patients with cancer who are colonized with vancomycin-resistant enterococci. Clin Infect Dis 35(10):1139 1146. doi:10.1086/342904

102. Lisboa LF, Miranda BG, Vieira MB, Dulley FL, Fonseca GG, Guimaraes T, Levin AS, Shikanai-Yasuda MA, Costa SF (2015) 
Empiric use of linezolid in febrile hematology and hematopoietic stem cell transplantation patients colonized with vancomycinresistant enterococcus spp. Int J Infect Dis 33:171-176. doi:10. 1016/j.ijid.2015.02.001

103. Teuffel O, Ethier MC, Alibhai SM, Beyene J, Sung L (2011) Outpatient management of cancer patients with febrile neutropenia: a systematic review and meta-analysis. Ann Oncol 22(11): 2358-2365. doi:10.1093/annonc/mdq745

104. Innes HE, Smith DB, O'Reilly SM, Clark PI, Kelly V, Marshall E (2003) Oral antibiotics with early hospital discharge compared with in-patient intravenous antibiotics for low-risk febrile neutropenia in patients with cancer: a prospective randomised controlled single centre study. Br J Cancer 89(1):43-49. doi:10.1038/sj.bjc. 6600993

105. Grillon A, Schramm F, Kleinberg M, Jehl F (2016) Comparative activity of ciprofloxacin, levofloxacin and moxifloxacin against Klebsiella pneumoniae, Pseudomonas aeruginosa and Stenotrophomonas maltophilia assessed by minimum inhibitory concentrations and time-kill studies. PLoS One 11(6):e0156690. doi:10.1371/journal.pone.0156690

106. Rolston KV, Frisbee-Hume S, LeBlanc B, Streeter H, Ho DH (2003) In vitro antimicrobial activity of moxifloxacin compared to other quinolones against recent clinical bacterial isolates from hospitalized and community-based cancer patients. Diagn Microbiol Infect Dis 47(2):441-449

107. Rubenstein EB, Rolston K, Benjamin RS, Loewy J, Escalante C, Manzullo E, Hughes P, Moreland B, Fender A, Kennedy K et al (1993) Outpatient treatment of febrile episodes in low-risk neutropenic patients with cancer. Cancer 71(11):3640-3646

108. Sipsas NV, Kosmas C, Ziakas PD, Karabelis A, Vadiaka M, Skopelitis E, Kordossis T, Tsavaris N (2007) Comparison of two oral regimens for the outpatient treatment of low-risk cancer patients with chemotherapy-induced neutropenia and fever: ciprofloxacin plus cefuroxime axetil versus ciprofloxacin plus amoxicillin/clavulanate. Scand J Infect Dis 39(9):786-791. doi:10.1080/ 00365540701367769

109. Ortega M, Rovira M, Almela M, de la Bellacasa JP, Carreras E, Mensa J (2004) Measurement of C-reactive protein in adults with febrile neutropenia after hematopoietic cell transplantation. Bone Marrow Transplant 33(7):741-744. doi:10.1038/sj.bmt.1704409

110. Hatzistilianou M, Rekliti A, Athanassiadou F, Catriu D (2010) Procalcitonin as an early marker of bacterial infection in neutropenic febrile children with acute lymphoblastic leukemia. Inflamm Res 59(5):339-347. doi:10.1007/s00011-009-0100-0

111. Sakr Y, Sponholz C, Tuche F, Brunkhorst F, Reinhart K (2008) The role of procalcitonin in febrile neutropenic patients: review of the literature. Infection 36(5):396-407. doi:10.1007/s15010-0087374-y

112. Secmeer G, Devrim I, Kara A, Ceyhan M, Cengiz B, Kutluk T, Buyukpamukcu M, Yetgin S, Tuncer M, Uludag AK, Tezer H, Yildirim I (2007) Role of procalcitonin and CRP in differentiating a stable from a deteriorating clinical course in pediatric febrile neutropenia. J Pediatr Hematol Oncol 29(2):107-111. doi:10. 1097/MPH.0b013e3180320b5b

113. Robinson JO, Lamoth F, Bally F, Knaup M, Calandra T, Marchetti $\mathrm{O}$ (2011) Monitoring procalcitonin in febrile neutropenia: what is its utility for initial diagnosis of infection and reassessment in persistent fever? PLoS One 6(4):e18886. doi:10.1371/journal. pone. 0018886

114. Engel A, Knoll S, Kern P, Kern WV (2005) Interleukin-8 serum levels at fever onset in patients with neutropenia predict early medical complications. Infection 33(5-6):380-382. doi:10.1007/ s15010-005-5068-2

115. El-Maghraby SM, Moneer MM, Ismail MM, Shalaby LM, ElMahallawy HA (2007) The diagnostic value of C-reactive protein, interleukin-8, and monocyte chemotactic protein in risk stratification of febrile neutropenic children with hematologic malignancies. J Pediatr Hematol Oncol 29(3):131-136. doi:10.1097/ MPH.0b013e3180308770

116. Buyukberber N, Buyukberber S, Sevinc A, Camci C (2009) Cytokine concentrations are not predictive of bacteremia in febrile neutropenic patients. Med Oncol (Northwood, London, England) 26(1):55-61. doi:10.1007/s12032-008-9081-z

117. Tromp YH, Daenen SM, Sluiter WJ, Vellenga E (2009) The predictive value of interleukin-8 (IL-8) in hospitalised patients with fever and chemotherapy-induced neutropenia. Eur J Cancer (Oxf, Engl: 1990) 45(4):596-600. doi:10.1016/j.ejca.2008.10.041

118. Heussel CP, Kauczor HU, Heussel G, Fischer B, Mildenberger P, Thelen M (1997) Early detection of pneumonia in febrile neutropenic patients: use of thin-section CT. AJR Am J Roentgenol 169(5):1347-1353. doi:10.2214/ajr.169.5.9353456

119. Heussel CP, Kauczor HU, Heussel GE, Fischer B, Begrich M, Mildenberger P, Thelen M (1999) Pneumonia in febrile neutropenic patients and in bone marrow and blood stem-cell transplant recipients: use of high-resolution computed tomography. J Clin Oncol 17(3):796-805. doi:10.1200/jco.1999.17.3.796

120. Bow EJ, Rotstein C, Noskin GA, Laverdiere M, Schwarer AP, Segal BH, Seymour JF, Szer J, Sanche S (2006) A randomized, open-label, multicenter comparative study of the efficacy and safety of piperacillin-tazobactam and cefepime for the empirical treatment of febrile neutropenic episodes in patients with hematologic malignancies. Clin Infect Dis 43(4):447-459. doi:10.1086/505393

121. Cometta A, Kern WV, De Bock R, Paesmans M, Vandenbergh M, Crokaert F, Engelhard D, Marchetti O, Akan H, Skoutelis A, Korten V, Vandercam M, Gaya H, Padmos A, Klastersky J, Zinner S, Glauser MP, Calandra T, Viscoli C (2003) Vancomycin versus placebo for treating persistent fever in patients with neutropenic cancer receiving piperacillin-tazobactam monotherapy. Clin Infect Dis 37(3):382-389. doi:10.1086/376637

122. Cometta A, Calandra T, Gaya H, Zinner SH, de Bock R, Del Favero A, Bucaneve G, Crokaert F, Kern WV, Klastersky J, Langenaeken I, Micozzi A, Padmos A, Paesmans M, Viscoli C, Glauser MP (1996) Monotherapy with meropenem versus combination therapy with ceftazidime plus amikacin as empiric therapy for fever in granulocytopenic patients with cancer. The International Antimicrobial Therapy Cooperative Group of the European Organization for Research and Treatment of Cancer and the Gruppo Italiano Malattie Ematologiche Maligne dell'Adulto Infection Program. Antimicrob Agents Chemother 40(5):1108-1115

123. Erjavec Z, de Vries-Hospers HG, Laseur M, Halie RM, Daenen S (2000) A prospective, randomized, double-blinded, placebocontrolled trial of empirical teicoplanin in febrile neutropenia with persistent fever after imipenem monotherapy. J Antimicrob Chemother 45(6):843-849

124. Link H, Hiddemann W, Maschmeyer G, Buchheidt D, Glass B, Cornely O, Wilhelm M, Helmerking M, Adam D (1997) Antimicrobial therapy in neutropenic patients with unexplained fever, PEG-study II. Onkologie 20(Suppl 1):132

125. Schiel X, Link H, Maschmeyer G, Glass B, Cornely OA, Buchheidt D, Wilhelm M, Silling G, Helmerking M, Hiddemann W, Ostermann H, Hentrich M (2006) A prospective, randomized multicenter trial of the empirical addition of antifungal therapy for febrile neutropenic cancer patients: results of the Paul Ehrlich Society for Chemotherapy (PEG) multicenter trial II. Infection 34(3):118-126. doi:10.1007/s15010-006-5113-9

126. Goldberg E, Gafter-Gvili A, Robenshtok E, Leibovici L, Paul M (2008) Empirical antifungal therapy for patients with neutropenia and persistent fever: systematic review and meta-analysis. Eur $\mathrm{J}$ Cancer (Oxf, Engl: 1990) 44(15):2192-2203. doi:10.1016/j.ejca. 2008.06.040 
127. Cordonnier C, Pautas C, Maury S, Vekhoff A, Farhat H, Suarez F, Dhedin N, Isnard F, Ades L, Kuhnowski F, Foulet F, Kuentz M, Maison P, Bretagne S, Schwarzinger M (2009) Empirical versus preemptive antifungal therapy for high-risk, febrile, neutropenic patients: a randomized, controlled trial. Clin Infect Dis 48(8): 1042-1051. doi:10.1086/597395

128. Maschmeyer G, Heinz WJ, Hertenstein B, Horst HA, Requadt C, Wagner T, Cornely OA, Löffler J, Ruhnke M (2013) Immediate versus deferred empirical antifungal (IDEA) therapy in high-risk patients with febrile neutropenia: a randomized, double-blind, placebo-controlled, multicenter study. Eur J Clin Microbiol Infect Dis 32(5):679-689. doi:10.1007/s10096-012-1794-4

129. Walsh TJ, Finberg RW, Arndt C, Hiemenz J, Schwartz C, Bodensteiner D, Pappas P, Seibel N, Greenberg RN, Dummer S, Schuster M, Holcenberg JS (1999) Liposomal amphotericin B for empirical therapy in patients with persistent fever and neutropenia. National Institute of Allergy and Infectious Diseases Mycoses Study group. N Engl J Med 340(10):764-771. doi:10.1056/ nejm199903113401004

130. Walsh TJ, Teppler H, Donowitz GR, Maertens JA, Baden LR, Dmoszynska A, Cornely OA, Bourque MR, Lupinacci RJ, Sable CA, dePauw BE (2004) Caspofungin versus liposomal amphotericin B for empirical antifungal therapy in patients with persistent fever and neutropenia. N Engl J Med 351(14):13911402. doi:10.1056/NEJMoa040446

131. Aguilar-Guisado M, Espigado I, Cordero E, Noguer M, Parody R, Pachon J, Cisneros JM (2010) Empirical antifungal therapy in selected patients with persistent febrile neutropenia. Bone Marrow Transplant 45(1):159-164. doi:10.1038/bmt.2009.125

132. Girmenia C, Micozzi A, Gentile G, Santilli S, Arleo E, Cardarelli L, Capria S, Minotti C, Cartoni C, Brocchieri S, Guerrisi V, Meloni G, Foa R, Martino P (2010) Clinically driven diagnostic antifungal approach in neutropenic patients: a prospective feasibility study. J Clin Oncol 28(4):667-674. doi:10.1200/jco.2009. 21.8032

133. Maertens J, Theunissen K, Verhoef G, Verschakelen J, Lagrou K, Verbeken E, Wilmer A, Verhaegen J, Boogaerts M, Van Eldere J (2005) Galactomannan and computed tomography-based preemptive antifungal therapy in neutropenic patients at high risk for invasive fungal infection: a prospective feasibility study. Clin Infect Dis 41(9):1242-1250. doi:10.1086/496927

134. Schneider T, Halter J, Heim D, Passweg J, Stern M, Tichelli A, Weisser M, Gerull S (2012) Pre-emptive diagnosis and treatment of fungal infections - evaluation of a single-centre policy. Clin Microbiol Infect 18(2):189-194. doi:10.1111/j.1469-0691.2011. 03589.x

135. Tan BH, Low JG, Chlebicka NL, Kurup A, Cheah FK, Lin RT, Goh YT, Wong GC (2011) Galactomannan-guided preemptive vs. empirical antifungals in the persistently febrile neutropenic patient: a prospective randomized study. Int J Infect Dis 15(5): e350-e356. doi:10.1016/j.ijid.2011.01.011

136. Walsh TJ, Pappas P, Winston DJ, Lazarus HM, Petersen F, Raffalli J, Yanovich S, Stiff P, Greenberg R, Donowitz G, Schuster M, Reboli A, Wingard J, Arndt C, Reinhardt J, Hadley S, Finberg R, Laverdiere M, Perfect J, Garber G, Fioritoni G, Anaissie E, Lee J (2002) Voriconazole compared with liposomal amphotericin $\mathrm{B}$ for empirical antifungal therapy in patients with neutropenia and persistent fever. N Engl J Med 346(4):225-234. doi:10.1056/ nejm200201243460403

137. Boogaerts M, Winston DJ, Bow EJ, Garber G, Reboli AC, Schwarer AP, Novitzky N, Boehme A, Chwetzoff E, De Beule $\mathrm{K}$ (2001) Intravenous and oral itraconazole versus intravenous amphotericin B deoxycholate as empirical antifungal therapy for persistent fever in neutropenic patients with cancer who are receiving broad-spectrum antibacterial therapy. A randomized, controlled trial. Ann Intern Med 135(6):412-422

138. Toubai T, Tanaka J, Ota S, Shigematsu A, Shono Y, Ibata M, Hashino S, Kondo T, Kakinoki Y, Masauzi N, Kasai M, Iwasaki H, Kurosawa M, Asaka M, Imamura M (2007) Efficacy and safety of micafungin in febrile neutropenic patients treated for hematological malignancies. Intern Med (Tokyo, Japan) 46(1):3-9

139. Yanada M, Kiyoi H, Murata M, Suzuki M, Iwai M, Yokozawa T, Baba H, Emi N, Naoe T (2006) Micafungin, a novel antifungal agent, as empirical therapy in acute leukemia patients with febrile neutropenia. Intern Med (Tokyo, Japan) 45(5):259-264

140. Kubiak DW, Bryar JM, McDonnell AM, Delgado-Flores JO, Mui E, Baden LR, Marty FM (2010) Evaluation of caspofungin or micafungin as empiric antifungal therapy in adult patients with persistent febrile neutropenia: a retrospective, observational, sequential cohort analysis. Clin Ther 32(4):637-648. doi:10.1016/ j.clinthera.2010.04.005

141. Jeong SH, Kim DY, Jang JH, Mun YC, Choi CW, Kim SH, Kim JS, Park JS (2016) Efficacy and safety of micafungin versus intravenous itraconazole as empirical antifungal therapy for febrile neutropenic patients with hematological malignancies: a randomized, controlled, prospective, multicenter study. Ann Hematol 95(2):337-344. doi:10.1007/s00277-015-2545-2

142. Smith TJ, Bohlke K, Lyman GH, Carson KR, Crawford J, Cross SJ, Goldberg JM, Khatcheressian JL, Leighl NB, Perkins CL, Somlo G, Wade JL, Wozniak AJ, Armitage JO (2015) Recommendations for the use of WBC growth factors: American Society of Clinical Oncology clinical practice guideline update. J Clin Oncol 33(28):3199-3212. doi:10.1200/jco.2015. 62.3488

143. Freifeld AG, Bow EJ, Sepkowitz KA, Boeckh MJ, Ito JI, Mullen CA, Raad II, Rolston KV, Young JA, Wingard JR (2011) Clinical practice guideline for the use of antimicrobial agents in neutropenic patients with cancer: 2010 update by the infectious diseases society of america. Clin Infect Dis 52(4):e56-e93. doi:10.1093/ $\mathrm{cid} / \mathrm{cir} 073$

144. Cornelissen JJ, Rozenberg-Arska M, Dekker AW (1995) Discontinuation of intravenous antibiotic therapy during persistent neutropenia in patients receiving prophylaxis with oral ciprofloxacin. Clin Infect Dis 21(5):1300-1302

145. Slobbe L, Waal L, Jongman LR, Lugtenburg PJ, Rijnders BJ (2009) Three-day treatment with imipenem for unexplained fever during prolonged neutropaenia in haematology patients receiving fluoroquinolone and fluconazole prophylaxis: a prospective observational safety study. Eur J Cancer (Oxford, England: 1990) 45(16):2810-2817. doi:10.1016/j.ejca.2009.06.025

146. Averbuch D, Orasch C, Cordonnier C, Livermore DM, Mikulska M, Viscoli C, Gyssens IC, Kern WV, Klyasova G, Marchetti O, Engelhard D, Akova M (2013) European guidelines for empirical antibacterial therapy for febrile neutropenic patients in the era of growing resistance: summary of the 2011 4th European conference on infections in leukemia. Haematologica 98(12):18261835. doi:10.3324/haematol.2013.091025

147. Averbuch D, Cordonnier C, Livermore DM, Mikulska M, Orasch C, Viscoli C, Gyssens IC, Kern WV, Klyasova G, Marchetti O, Engelhard D, Akova M (2013) Targeted therapy against multiresistant bacteria in leukemic and hematopoietic stem cell transplant recipients: guidelines of the 4th European conference on infections in leukemia (ECIL-4, 2011). Haematologica 98(12): 1836-1847. doi:10.3324/haematol.2013.091330 